\title{
Using aircraft measurements to determine the refractive index of Saharan dust during the DODO Experiments
}

\author{
C. L. McConnell ${ }^{1}$, P. Formenti ${ }^{2}$, E. J. Highwood ${ }^{3}$, and M. A. J. Harrison ${ }^{4}$ \\ ${ }^{1}$ Department of Physics, Imperial College, London, UK \\ ${ }^{2}$ LISA, CNRS, Université Paris 12, Créteil, France \\ ${ }^{3}$ Department of Meteorology, University of Reading, UK \\ ${ }^{4}$ Met Office, Exeter, UK
}

Received: 1 September 2009 - Published in Atmos. Chem. Phys. Discuss.: 5 November 2009

Revised: 23 March 2010 - Accepted: 23 March 2010 - Published: 31 March 2010

\begin{abstract}
Much uncertainty in the value of the imaginary part of the refractive index of mineral dust contributes to uncertainty in the radiative effect of mineral dust in the atmosphere. A synthesis of optical, chemical and physical in-situ aircraft measurements from the DODO experiments during February and August 2006 are used to calculate the refractive index mineral dust encountered over West Africa. Radiative transfer modeling and measurements of broadband shortwave irradiance at a range of altitudes are used to test and validate these calculations for a specific dust event on 23 August 2006 over Mauritania. Two techniques are used to determine the refractive index: firstly a method combining measurements of scattering, absorption, size distributions and Mie code simulations, and secondly a method using composition measured on filter samples to apportion the content of internally mixed quartz, calcite and iron oxideclay aggregates, where the iron oxide is represented by either hematite or goethite and clay by either illite or kaolinite. The imaginary part of the refractive index at $550 \mathrm{~nm}\left(n_{i}^{550}\right)$ is found to range between $0.0001 \mathrm{i}$ to $0.0046 \mathrm{i}$, and where filter samples are available, agreement between methods is found depending on mineral combination assumed. The refractive indices are also found to agree well with AERONET data where comparisons are possible. $n_{i}^{550}$ is found to vary with dust source, which is investigated with the NAME model for each case. The relationship between both size distribution and $n_{i}^{550}$ on the accumulation mode single scattering albedo at $550 \mathrm{~nm}\left(\omega_{0}^{550}\right)$ are examined and size distribution is found to have no correlation to $\omega_{0}^{550}$, while $n_{i}^{550}$ shows a strong
\end{abstract}

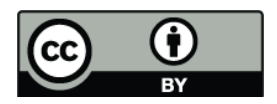

Correspondence to: C. L. McConnell (c.ryder@imperial.ac.uk) linear relationship with $\omega_{0}^{550}$. Radiative transfer modeling was performed with different models (Mie-derived refractive indices, but also filter sampling composition assuming both internal and external mixing). Our calculations indicate that Mie-derived values of $n_{i}^{550}$ and the externally mixed dust where the iron oxide-clay aggregate corresponds to the goethite-kaolinite combination result in the best agreement with irradiance measurements. The radiative effect of the dust is found to be very sensitive to the mineral combination (and hence refractive index) assumed, and to whether the dust is assumed to be internally or externally mixed.

\section{Introduction}

Mineral dust is an important component of the Earth's atmosphere, affecting climate principally through the direct radiative effect and through the deposition of dust to the ocean. Recent estimates of the dust anthropogenic net (shortwave plus longwave) radiative forcing from the Intergovernmental Panel on Climate Change (IPCC) range from -0.3 to $+0.1 \mathrm{Wm}^{-2}$ (Forster et al., IPCC, 2007), therefore putting a greater emphasis on the negative forcings than the previous IPCC 2001 report estimates of -0.6 to $+0.4 \mathrm{Wm}^{-2}$ (Penner et al., IPCC, 2001). This change has largely been due to more recent models using higher single scattering albedo $\left(\omega_{0}\right)$ values, of approximately 0.96 at $670 \mathrm{~nm}$, than previous simulations.

However, recent field campaign measurements have shown that considerable variation and uncertainty in $\omega_{0}$ remains, with values ranging from 0.79 at $532 \mathrm{~nm}$ (Otto et al., 2009) to as high as 0.99 at $550 \mathrm{~nm}$ (Osborne et al. (2008), McConnell et al., 2008) for Saharan dust. These values in

Published by Copernicus Publications on behalf of the European Geosciences Union. 
fact span the World Meteorological Organisation (WMO) (WCP, 1986) value that was and is used in many studies. These differences are at least in part attributed to the different size distributions and chemical composition measured in each case. The morphology and mixing state of different mineral constituents can also have an impact on the optical properties (Mishchenko et al., 1997; Sokolik and Toon, 1999).

The role of composition in affecting optical properties such as the single scattering albedo is parameterised by the complex refractive index $\mathrm{n}$, which is of key importance in determining the optical properties of dust. While the real part $\left(n_{r}\right)$, which determines the amount of scattering, is relatively well defined, and ranges between 1.51 to 1.56 (e.g. Shettle and Fenn, 1979; Balkanski et al., 2007; Otto et al., 2009), estimates of the imaginary part $\left(n_{i}\right)$, defining the amount of absorption, show variations of almost two orders of magnitude at wavelengths of around $550 \mathrm{~nm}$. For example, estimates of $n_{i}$ at $550 \mathrm{~nm}\left(n_{i}^{550}\right)$ range from as small as $0.0004 \mathrm{i}$ (Osborne et al., 2008) to as large as 0.008i (Shettle and Fenn, 1979; WMO, 1986), with a large number of studies estimating values between 0.001i and 0.006i (e.g. Patterson et al., 1977; Dubovik et al., 2002; Haywood et al., 2003; Kandler et al., 2007; Petzold et al., 2009; Otto et al., 2009).

Variation in $n_{i}$ can be due to variable composition (e.g. Sokolik et al., 1993; Sokolik and Toon, 1999), since mineral dust can be a complicated mixture of various minerals, each having different refractive indices, in varying proportions according to their source region of emission. In particular, internal mixtures can result in different optical properties to external mixtures. The amount and type of absorbing iron oxides present, such as hematite $\left(\mathrm{Fe}_{2} \mathrm{O}_{3}\right)$ and goethite $(\mathrm{FeO}-\mathrm{OH})$, are also thought to be of crucial importance in controlling the to the amount and the spectral dependence of absorption at UV and visible wavelengths (Sokolik and Toon, 1999; Lafon et al., 2006). The content and speciation of iron oxides have been found to vary with source (e.g. Formenti et al., 2008), with Sahelian sources being generally richer in absorbing iron oxides than the Saharan ones (e.g. Claquin et al., 1999; Formenti et al., 2008). Furthermore, internal mixtures can result in different optical properties to external mixtures.

Limited case studies of in-situ measurements exist to provide data on both the refractive index and optical properties of dust. Considering the large range in estimates of both $\omega_{0}$ and $n_{i}$, it is important to use in-situ measurements of dust, where available, to constrain their variation. In this study we take advantage of the large number of in-situ measurements from the DODO (Dust Outflow and Deposition to the Ocean) aircraft campaigns, which took place over the West Africa during February and August 2006. These encompass measurements of dust in both the dry and wet season, when the meteorology allowing dust transport is significantly different.

We use a synthesis of aircraft measurements to determine and validate the refractive index of dust, including in-situ chemical composition and optical measurements, as well as pyranometer measurements of broadband upwelling and downwelling irradiance at different altitudes which are then compared to radiative transfer model irradiances. This is in contrast to previous studies, which use only one or two components out of in-situ composition measurements, size distribution measurements or radiation measurements to constrain the refractive index (e.g. Petzold et al., 2009; Haywood et al., 2003). This methodology is sometimes referred to as "radiative closure" (e.g. Highwood et al., 2003). Where possible, refractive indices are compared to ground-based AERONET retrievals. The relative importance of dust source, composition and size distribution to the optical properties is assessed.

\section{Methodology}

\subsection{Flight information}

During the DODO aircraft campaigns a series of flights was carried out by the FAAM BAe-146 over Mauritania and the tropical east Atlantic Ocean during February (DODO1) and August (DODO2) 2006. Full details of flight dates, locations and times as well as instrumentation information are shown in McConnell et al. (2008). Measurements were collected for different dust events, comprising 40 measurements of different dust layers at different altitudes. Each of these measurements is an average over an aircraft "run" (abbreviated to R), during which time the aircraft remained at a constant altitude for between 5 to $30 \mathrm{~min}$, covering between 30 to $200 \mathrm{~km}$.

\subsection{Calculation of refractive indices using Mie code}

For each run, measurements of scattering and absorption from a nephelometer (3563, TSI Inc.) and a PSAP (Particle Soot Absorption Photometer) were used to calculate $\omega_{0}^{550}$, as shown in McConnell et al. (2008). The passing efficiency of the aircraft inlet from which these two instruments are sampling mean that the measurements of $\omega_{0}^{550}$ are representative of the accumulation mode only, which is defined here as representing particles of less than $3 \mu \mathrm{m}$ optical diameter.

Size distributions for the accumulation mode were measured by a PCASP (Passive Cavity Aerosol Spectrometer Probe, diameter $0.1-3.0 \mu \mathrm{m}$ ) for the same runs (as shown in McConnell et al. (2008), Fig. 6). In this study, each size distribution measurement (one for each run) has been represented by a logfit curve, which is the sum of four lognormal modes which are specified for each individual dust case. A logfit curve is used in order to allow the size distributions to be easily replicated through using lognormal mode parameters, to increase the resolution of the size distribution measurements, and to smooth out any instrumental noise.

For each of the 40 runs, the size distribution was used in a Mie scattering code to calculate optical properties at $550 \mathrm{~nm}$. For the refractive index $n_{r}^{550}$ was assumed to be 1.53 (as in 
WMO, 1986). $n_{i}^{550}$ was iterated until $\omega_{0}^{550}$ from the Mie scattering code matched $\omega_{0}^{550}$ from the observations, to within 0.0001 . Thus $n_{i}^{550}$ was derived individually for each run. Errors in $n_{i}^{550}$ were also calculated based on the errors in $\omega_{0}^{550}$ due to the larger of either instrumental error or atmospheric variability, across the distance over which they were measured. The $n_{i}^{550}$ values are representative of the accumulation mode only, since they are derived from size distributions, scattering and absorption measurements which represent only the accumulation mode.

These calculations involve the assumption that the value $n_{r}^{550}$ is 1.53 at $550 \mathrm{~nm}$, though values in the literature suggest a range from 1.51 to 1.56 . A sensitivity test using this range of $n_{r}^{550}$ values showed that the derived $n_{i}^{550}$ values were not very sensitive to the value of $n_{r}^{550}$ used, and changed by less than $0.0002 \mathrm{i}$ under these conditions.

The Mie calculations of $n_{i}^{550}$ assume that the dust particles are spherical. Mineral dust particles have frequently been found to be composed of non-spherical particles (e.g. Reid et al., 2003b; Kandler et al., 2007; Chou et al., 2008; Otto et al., 2009; Chou et al., 2008). This non-sphericity can result in a different phase function (Mishchenko et al., 1997). However, if properties such as the phase function are integrated over hemispheres (giving the asymmetry parameter) then differences in the shape of the phase function become less important. Additionally, if irradiances, rather than radiances, are modelled, then spherical assumptions lead to errors on the order of a few percent (Mishchenko, 1993; Mishchenko et al., 1995). Likewise, work by Otto et al. (2009) found that single scattering albedo values were in error by up to $1 \%$ due to spherical assumptions. These errors are therefore smaller than the differences in single scattering albedo for different cases used in Sect. 3.1 to determine $n_{i}^{550}$.

\subsection{Calculation of refractive indices from filter composition measurements}

The real and imaginary parts of the dust refractive index can also be calculated as volume-weighed sum of the refractive indices of the different constituents, and an appropriate mixing rule to describe their mixing state (Bohren and Huffmann, 1983). To do so, we used the composition and mixing state data obtained by analysis of the dust filter samples collected onboard the aircraft. We calculate optical properties based on both internal and external mixing assumptions.

During DODO, aerosols were collected on polycarbonate filters during straight and level runs as presented in Formenti et al. (2008) and McConnell et al. (2008). Filter collection on the BAe-146 is performed from a different set of inlets than those used by the PSAP and nephelometer to measure the scattering and absorption coefficients. Although the passing efficiency of those filter lines is not formally determined, they should represent more of the coarse mode than the PCASP, nephelometer and PSAP measurements. Elec- tron microscopy analysis of the filter samples has shown that large particles up to $10-15 \mu \mathrm{m}$ (aerodynamic diameter) are collected (Chou et al., 2008), although it is likely that filter sampling overestimates the number of coarse particles compared to on-line PCASP measurements due to sub-isokinetic sampling effects. Furthermore, a previous aircraft-to-ground comparison indicated that the $35 \%$ of the sea salt coarse mode mass fraction was retrieved by aircraft filter sampling (Andreae et al., 2000).

Depending on the collected mass, samples from DODO were analysed by different bulk techniques to yield the elemental and the mineralogical composition (by X-ray fluorescence and $\mathrm{X}$-ray diffraction), as well as the total iron oxide content (by chemical extraction based on citrate-bicarbonatedithionite (CBD) reagent) and its speciation in its main oxides, hematite $\left(\mathrm{Fe}_{2} \mathrm{O}_{3}\right)$ and goethite $(\mathrm{FeOOH})$ (by diffuse reflectance spectroscopy; Formenti et al., 2008). Nevertheless, results from these analyses could not be used in a straightforward way to estimate the bulk aerosol composition: first, not all the DODO samples were loaded enough to be analysed by X-ray diffraction or diffuse reflectance spectroscopy (see Formenti et al., 2008); second, results have to be regarded as semi-quantitative owing to the difficulty of disposing of calibration references being representative of the actual aerosol matrix composition (Caquineau et al., 1998; Kosmas et al., 1984).

To overcome these difficulties in DODO, the composition of dust collected on the filter samples was estimated from the elemental concentrations measured by X-ray fluorescence and from the iron oxide content measured by CBD. This approach has been used previously by Lafon et al. (2006) on laboratory-generated dust aerosols. Based on the semi-quantitative results of X-ray diffraction and diffuse reflectance spectroscopy, dust was represented as a mixture of quartz $\left(\mathrm{SiO}_{2}\right)$, calcite $\left(\mathrm{CaCO}_{3}\right)$, and iron oxide-clay aggregates. These aggregates are internal mixtures of iron oxides (either as hematite or goethite) and clays (either as illite or kaolinite).

The relative proportions of the above-mentioned minerals were estimated from the elemental concentrations of $\mathrm{Al}$ (for clays), $\mathrm{Ca}$ (for calcite), $\mathrm{Si}$ (for quartz) measured in the dust samples (see Table 2). The volume fraction of iron oxides in the aggregates was estimated from the ratio of $\mathrm{Fe}$ in the oxide form to the total element Fe, and is shown in Table 1 (again see Lafon et al. (2006) for further details). Because of the impossibility of apportioning $\mathrm{Al}$ into illite and kaolinite, nor Fe oxide into hematite and goethite, four types of aggregates were tested: (HI), where all the $\mathrm{Al}$ is represented as illite and all the $\mathrm{Fe}$ oxide as hematite; (HK), where all the $\mathrm{Al}$ is represented as kaolinite and all the Fe oxide as hematite; (GI), where all the $\mathrm{Al}$ is represented as illite and all the $\mathrm{Fe}$ oxide as goethite; and (GK) where all the $\mathrm{Al}$ is represented as kaolinite and all the Fe oxide as goethite. The volume proportions of iron oxides in relation to the iron oxide clay aggregate can be seen in Table 1, and varied slightly as a function of aircraft 
Table 1. Volume fraction of iron oxide used in the clay matrix for runs where filter sample data was used to calculate a refractive index

\begin{tabular}{llllll}
\hline & b238 R3.1 & b238 R4.1 & b238 R5.1 & b242 R1.1 & b242 R5.1 \\
\hline HI & 0.035 & 0.037 & 0.035 & 0.033 & 0.033 \\
HK & 0.051 & 0.055 & 0.051 & 0.048 & 0.048 \\
GI & 0.042 & 0.045 & 0.042 & 0.040 & 0.040 \\
GK & 0.062 & 0.066 & 0.062 & 0.058 & 0.058 \\
\hline
\end{tabular}

Table 2. Volume fraction of minerals used for each run where filter sample data was used to calculate a refractive index

\begin{tabular}{llllll}
\hline & $\mathrm{b} 238 \mathrm{R} 3.1$ & $\mathrm{~b} 238 \mathrm{R} 4.1$ & $\mathrm{~b} 238 \mathrm{R} 5.1$ & $\mathrm{~b} 242 \mathrm{R} 1.1$ & $\mathrm{~b} 242 \mathrm{R} 5.1$ \\
\hline Calcite & 0.10 & 0.13 & 0.10 & 0.08 & 0.08 \\
Quartz & 0.31 & 0.32 & 0.34 & 0.33 & 0.33 \\
Iron oxide-clay aggregate & 0.59 & 0.54 & 0.57 & 0.59 & 0.59 \\
\hline
\end{tabular}

run. The complex refractive indices of the iron oxide-clay aggregates were calculated using the Bruggeman approximation for internal mixtures as in Sokolik and Toon (1999) and Lafon et al. (2006).

Next, two different techniques were used to represent both internal and external mixtures of quartz, calcite and iron oxide clay aggregates. For the internal mixtures, a volume mixing rule was used to determine the final refractive index from the individual refractive indices of the proportions of quartz, calcite, and iron oxide-clay aggregates. These volume proportions are shown in Table 2 as a function of aircraft run. Henceforth, HI_int, HK_int, GI_int and GK_int will indicate the composition of these final internal mixtures. Refractive indices of kaolinite, illite, calcite and quartz were derived by references cited in Sokolik and Toon (1999), whereas for hematite and goethite (at visible wavelengths), we used the refractive indices as reported by Bédidi and Cervelle (1993).

For the external mixtures, optical properties (scattering, absorption and asymmetry parameter) for each of the individual refractive index components (quartz, calcite and the iron oxide clay aggregates) were calculated using a Mie scattering code. The optical properties of the full external mixture was then calculated by weighting each component by the values shown in Table 2 (assuming that all minerals had the same size distribution) and summing over each component. Therefore only the optical properties for external mixing are shown (and the refractive indices are not). The optical properties of the external mixture are solely calculated for one case, R4.1 from flight b238, which is used for the radiative transfer calculations (along with the internal mixture cases) described in Sect. 2.5. The external mixing cases are denoted HI_ext, HK_ext, GI_ext and GK_ext, to indicate the type of iron oxide and clay used in the aggregates.

SEM analyses of dust for both DODO and for other cases (McConnell et al., 2008; Chou et al., 2008; Lafon et al.,
2006) have shown that there is no evidence of internal mixing between minerals - quartz, carbonates and clays are not internally mixed, while iron oxides can be either internally or externally mixed to clays, but external mixing is more frequent, and therefore the technique of Lafon et al. (2006) using external mixing, as used in this study, is more appropriate for representing dust. For comparison purposes, and in order to directly compare filter-derived refractive indices to the Mie refractive indices, we also include the internal mixing cases.

\subsection{Modeling of air mass origins}

Air mass origins for each dust case have been investigated using NAME (Numerical Atmospheric-dispersion Modeling Environment; Ryall and Maryon, 1998), as described in McConnell et al. (2008). In order to identify potential source regions of the dust observed, NAME was initiated at locations and times where the aircraft measured dust, and run backwards in time over five days by meteorological fields from the Met Office Unified Model (Cullen, 1993). Locations where the air parcels fall within $200 \mathrm{~m}$ of the surface are taken to indicate potential areas of dust uplift. The results do not take into account properties such as surface wind speed and surface properties (such as moisture, vegetation and soil composition), and therefore the results solely indicate regions of potential dust uplift.

\subsection{Radiative transfer model}

During flight b238 on 23 August 2006, the aircraft measured significant dust loadings over the Mauritanian desert, with optical depths reaching 1.5-2.0 at 550 nm (McConnell et al., 2008; Greed et al., 2008). This dust event has been modelled in the two-stream Edwards and Slingo (hereafter ES96) radiative transfer model for a single column (Edwards and Slingo, 1996). This flight has been specially selected for a 
detailed investigation of radiative closure based on the availability of chemical composition measurements (see Sect. 2.3) and the large amount of dust present, which means that the radiative effect is significant. Size distribution measurements of the coarse mode are also available. Shortwave upwards and downwards irradiances have been computed at specific pressures and solar zenith angles using ES96 in order to allow comparisons with the aircraft pyranometer measurements of irradiance at various altitudes within the dust profile.

Broadband shortwave irradiances are calculated in ES96 using 220 spectral bands, covering wavelengths from 0.2 to $10 \mu \mathrm{m}$. Additionally ES96 is run for wavelengths from 549 to $556 \mathrm{~nm}$ to allow the calculation of the aerosol optical depth (AOD) at $550 \mathrm{~nm}$. A Lambertian surface albedo of $0.44 \pm 0.1$ is used, which has been calculated from up and downwelling broadband aircraft pyranometer measurements averaged over three low altitude runs at $300 \mathrm{~m}$, the lowest altitude permitted for the BAe-146 over the desert surface. The surface albedo is therefore broadband, covering the spectral range of 0.3 to $3 \mu \mathrm{m}$. The uncertainty is the range of values measured over the three low altitude runs. Solar parameters are specified for 23 August 2006.

The vertical profile of atmospheric components is specified on 51 pressure levels, resulting in a resolution of around $200 \mathrm{~m}$ in the lower atmosphere where dust is present. Vertical profiles of ozone, temperature, dust and water vapour are obtained from aircraft measurements from a combination of aircraft profiles covering altitudes from $300 \mathrm{~m}$ to $5750 \mathrm{~m}$. Below $300 \mathrm{~m}$, a constant profile of ozone, dust and water vapour is assumed, while temperature is extended to the surface using the lapse rate from the lowest portion of the aircraft profile. Above $5750 \mathrm{~m}$, where aircraft measurements are also unavailable, data were obtained from McClatchey et al. (1971) standard tropical climatology profiles. Full vertical profiles for carbon dioxide, oxygen, methane, CFCs and $\mathrm{N}_{2} \mathrm{O}$ for the entire profile were also obtained from McClatchey et al. (1971).

We calculate the diurnally averaged shortwave aerosol radiative effect (ARE) of the dust observed during flight b238 using the modeled irradiances, using the standard convention that positive values indicate warming, and negative values indicate cooling. The aerosol radiative effect is defined as the difference in the net irradiance (i.e. downwards minus upwards, or net incoming) between cases when aerosol is present, and when aerosol is absent, as shown in Eq. (1). This is consistent with the IPCC 2007 report (Forster et al., 2007).

$\mathrm{ARE}_{\mathrm{lev}}=\mathrm{NET}_{\mathrm{lev}}^{\mathrm{aer}}-\mathrm{NET}_{\mathrm{lev}}^{\mathrm{clr}}$

In Eq. (1), NET is the net shortwave irradiance at a model level (lev), and aer indicates aerosol is present, while clr indicates that no aerosol is present in the model. In this study we calculate ARE values both at the surface (SFC) and at the top of the atmosphere (TOA). In a similar manner we also calculate the shortwave atmospheric direct aerosol radiative effect (ARE $E_{\text {ATM }}$ ) using Eq. (2), which shows the net heating of the atmosphere due to the presence of the aerosol.

$$
\mathrm{ARE}_{\mathrm{ATM}}=\mathrm{ARE}_{\mathrm{TOA}}-\mathrm{ARE}_{\mathrm{SFC}}
$$

\subsection{Aircraft pyranometer measurements}

During DODO the BAe-146 made measurements of up and downwelling irradiance using Eppley Precision Spectral Pyranometers mounted on the upper and lower fuselage of the aircraft. The pyranometers are covered with Schott glass, which determines the spectral range of the measurements to be $0.3-3 \mu \mathrm{m}$ (Haywood et al., 2003). The pyranometer measurements are corrected for the pitch and roll angle of the aircraft and the cosine effect. Measurements obtained from the upper pyranometer while the aircraft was heading within $\pm 50^{\circ}$ of the solar azimuth were discarded due to aerosol-induced dirtying on the front of the pyranometer dome, which resulted in reduced irradiance (by up to $11 \%$ ) during these portions of the flight. The uncertainty in the upper pyranometer measurements is estimated at $5.5 \%$ based on uncertainties in pitch and roll corrections, calibration error, and on comparisons with ES96 from aircraft manoeuvres during different flights at high altitudes, i.e. above aerosol and cloud (McConnell, 2008). The uncertainty of the lower pyranometers is more difficult to determine since their location on the aircraft prevented measurements of clear sky irradiance, and is presently undetermined. Pyranometer measurements from flight b238 were averaged over horizontal runs at various altitudes, and cloud-contaminated data were discarded.

\section{Results}

\subsection{Refractive indices}

Figure 1 shows the $n_{i}^{550}$ values derived using a Mie scattering code (solid circles), and associated errors for a series of aircraft runs from various flights during DODO. Refractive indices from filter samples based on internal mixing assumptions are also shown where sufficient loading permitted (see Sect. 2.3). The Mie-derived $n_{i}^{550}$ values show a large amount of variability and range from $0.0001 \mathrm{i}$ to $0.0046 \mathrm{i}$. Other than the results for b168 R15 and R16, the dry season dust has low $n_{i}^{550}$ values (below $0.001 i$ ), whereas the wet season dust shows a much greater range in absorption. Two flights with relatively more absorbing dust stand out $-\mathrm{R} 15$ and R16 from flight b168, and R1.1 and R5.1 from flight b242, with $n_{i}^{550}$ values of $0.0046 \mathrm{i}, 0.0038 \mathrm{i}, 0.0026 \mathrm{i}$ and $0.0042 \mathrm{i}$ respectively.

Table 3 and Fig. 1 also display the refractive indices obtained from the filter samples (internal mixing) and compare them to the Mie-derived refractive indices for the same cases. Table 3 shows the values of the refractive indices for selected cases where either filter sample refractive indices 


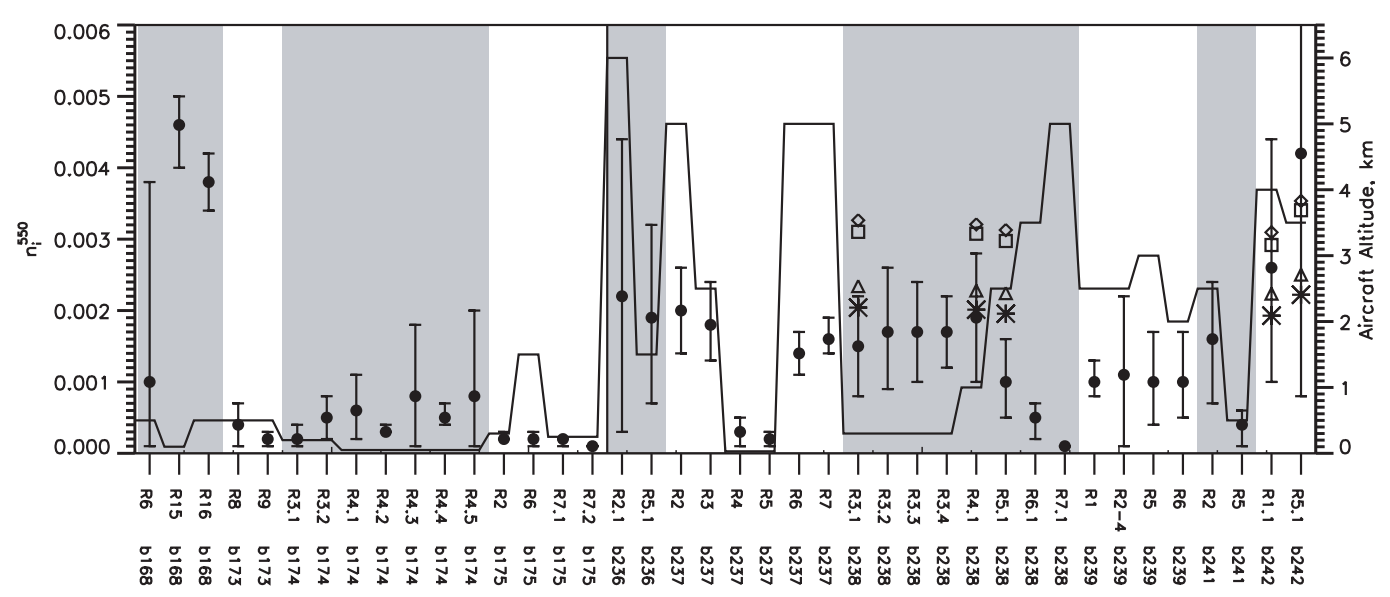

Fig. 1. Imaginary refractive indices at $550 \mathrm{~nm}$. Solid circles show $n_{i}^{550}$ values derived from Mie scattering code for the accumulation mode. Filter sample $n_{i}^{550}$ values (where available) for different mineral combinations assuming internal mixing are indicated by diamonds (HI_int), squares (HK_int), triangles (GI_int) and asterisks (GK_int). The solid line shows the aircraft altitude where the measurements were taken. Shaded panels group results from the same flight (flight numbers are preceded by "b", run numbers by "R"). Error bars represent the range in $n_{i}^{550}$ expected from the uncertainty in single scattering albedo (due to both instrumental error and atmospheric variability). Note that the large error bars for b168 R6, b236 R2.1 and b242 are due to large atmospheric variability over these runs.

or AERONET retrievals of refractive index are available to compare against the Mie-derived refractive indices. We note again that each technique represents a slightly different size distribution range: the Mie-derived results represent the accumulation mode only (up to $d=3 \mu \mathrm{m}$ ), the filters include some of the accumulation mode (up to around $d=15 \mu \mathrm{m}$, see Sect. 2.3), and the AERONET results represent the size range $0.1 \mu \mathrm{m}<d<30 \mu \mathrm{m}$ (Dubovik et al., 2002).

For flight b242 the $n_{i}^{550}$ values for each technique are in agreement within the bounds of error, though notably for flight b242 the errors are large due to the large spatial variability in measured absorption and scattering coefficients. For flight b238 the errors in $n_{i}^{550}$ are smaller than those for b242. For the b238 cases, the filters GK_int cases agree with the Mie derived $n_{i}^{550}$ results for two out of the three runs where filters data was available. For b238 R4.1, the GI_int and Mie results are also in agreement. However, for all cases examined for b238, the filter assumptions using HI int and HK_int all fall outside the bounds of error for the Mie-derived results.

Since the Mie-derived values refer only to the accumulation mode, whilst the filter samples include at least part of the coarse mode, if the composition of the dust is dependent on particle size, then this could lead to a difference in $n_{i}^{550}$ values. In this context, it is therefore interesting that for flight b242, where the dust was transported in an elevated layer over the ocean and the coarse mode fraction was small, the $n_{i}^{550}$ values are in agreement between the results derived from Mie code and from the filter samples. Contrastingly, for flight b238, a substantial dust storm over the Mauritanian desert with substantial coarse mode present, the values $n_{i}^{550}$ differ between the filter samples and the Mie-derived esti- mates. This therefore suggests that the lesser agreement for b238 is due to the greater influence of the coarse mode which the Mie-derived refractive indices do not incorporate.

The discrepancy between the filters and Mie-derived results for flight b238 presented here suggest that the larger particles are more absorbing, which is consistent with the findings of Petzold et al. (2009) from Morocco, but not with those of Kandler et al. (2007) (Tenerife) where the smaller (externally mixed) particles had a greater contribution from both absorbing iron oxide and soot. Otto et al. (2009) (again in Morocco) found the smallest particles to be the least absorbing, but in that study a large proportion of the smaller particles were sulphate. Size resolved composition data for one run from flight b237 and from flight b238 for a small number of particles obtained using scanning and transmission electron microscopy (not shown) did indicate composition differences between the accumulation and the coarse modes, although neither sulphate nor soot particles were present in the DODO samples. Indeed, the analysis showed that there was no indication of any species other than dust present in the DODO aerosol presented here. We do not present the results from these analyses based on the low significance of the results due to the small number of particles sampled. However, the differences indicated that in both accumulation and coarse modes, most particles were aluminosilicates, carbonate and quartz, in relatively similar proportions in both modes. For flight b238, the coarse mode had a greater proportion of feldspars, whereas gypsum, iron oxides and titanium oxides were found in the fine mode only. Flight b237 showed similar features.

Table 3 also shows comparisons with AERONET refractive index retrievals from the ground-based site of Dakar 
Table 3. Comparison of selected refractive indices obtained from Mie code as shown in Fig. 1, filter samples assuming internal mixing, and the Dakar AERONET station retrievals. Min and max refer to the minimum and maximum $n_{i}^{550}$ shown by the error bars in Fig. 1 . AERONET data is from Level 1.5 Version 2.0 retrievals. See text for a description of the size ranges represented. ${ }^{*}$ indicates no data available. Where this relates to filter samples, this is due to low mass loadings on each filter sample.

\begin{tabular}{|c|c|c|c|c|c|c|c|}
\hline \multirow{2}{*}{$\begin{array}{l}\text { Flight and } \\
\text { Run }\end{array}$} & \multirow{2}{*}{$\begin{array}{l}\text { Sampling } \\
\text { Altitude }\end{array}$} & \multirow{2}{*}{$n_{i}^{550}$ from Mie (min, max) } & \multicolumn{4}{|c|}{$n_{r}^{550}-n_{i}^{550}$ from Filter Samples } & \multirow{2}{*}{$\begin{array}{l}\text { AERONET } n_{r}-n_{i} \text { at } \\
440 \mathrm{~nm}, 675 \mathrm{~nm}\end{array}$} \\
\hline & & & HI_int & HK_int & GI_int & GK_int & \\
\hline \multicolumn{8}{|c|}{ Flight b237, 22 August 2006, dust over Atlantic ocean to the north of Dakar } \\
\hline b237 R4 & $30 \mathrm{~m}$ & $\begin{array}{l}0.0003 \mathrm{i} \\
(0.0001,0.0011)\end{array}$ & $*$ & $*$ & $*$ & $*$ & \\
\hline b237 R5 & $30 \mathrm{~m}$ & $\begin{array}{l}0.0002 \mathrm{i} \\
(0.0001,0.0003)\end{array}$ & * & * & * & * & \\
\hline b237 R3 & $2.5 \mathrm{~km}$ & $\begin{array}{l}0.0018 \mathrm{i} \\
(0.0013,0.0024)\end{array}$ & * & * & * & $*$ & $\begin{array}{l}1.49-0.0037 \mathrm{i} \\
1.52-0.0010 \mathrm{i}\end{array}$ \\
\hline b237 R2 & $5 \mathrm{~km}$ & $\begin{array}{l}0.0020 \mathrm{i} \\
(0.0014,0.0026)\end{array}$ & * & * & * & * & \\
\hline b237 R6 & $5 \mathrm{~km}$ & $\begin{array}{l}0.0014 \mathrm{i} \\
(0.0011,0.0017)\end{array}$ & $*$ & * & $*$ & $*$ & \\
\hline b237 R7 & $5 \mathrm{~km}$ & $\begin{array}{l}0.0016 \mathrm{i} \\
(0.0014,0.0019)\end{array}$ & $*$ & * & $*$ & $*$ & \\
\hline \multicolumn{8}{|c|}{ Flight b238, 23 August 2006, heavy dust storm over Mauritania } \\
\hline b238 R3.1 & $300 \mathrm{~m}$ & $\begin{array}{l}0.0015 \mathrm{i} \\
(0.0008,0.0022)\end{array}$ & $\begin{array}{l}1.51- \\
0.0033 \mathrm{i}\end{array}$ & $\begin{array}{l}1.56- \\
0.0031 \mathrm{i}\end{array}$ & $\begin{array}{l}1.49- \\
0.0023 \mathrm{i}\end{array}$ & $1.54-0.0020$ & \\
\hline b238 R4.1 & $1 \mathrm{~km}$ & $\begin{array}{l}0.0019 \mathrm{i} \\
(0.0010,0.0028)\end{array}$ & $\begin{array}{l}1.52- \\
0.0032 \mathrm{i}\end{array}$ & $\begin{array}{l}1.56- \\
0.0031 \mathrm{i}\end{array}$ & $\begin{array}{l}1.50- \\
0.0023 \mathrm{i}\end{array}$ & $\begin{array}{l}1.54- \\
0.0020 \mathrm{i}\end{array}$ & \\
\hline b238 R5.1 & $2.5 \mathrm{~km}$ & $\begin{array}{l}0.0010 \mathrm{i} \\
(0.0005,0.0016)\end{array}$ & $\begin{array}{l}1.51- \\
0.0031 \mathrm{i}\end{array}$ & $\begin{array}{l}1.56- \\
0.0030 \mathrm{i}\end{array}$ & $1.50-0.0022$ & $1.54-0.0020$ & $\begin{array}{l}1.52-0.0014 \mathrm{i} \\
1.52-0.0008 \mathrm{i}\end{array}$ \\
\hline b238 R6.1 & $3.5 \mathrm{~km}$ & $\begin{array}{l}0.0005 \mathrm{i} \\
(0.0002,0.0007)\end{array}$ & * & * & $*$ & $*$ & \\
\hline b238 R7.1 & $5 \mathrm{~km}$ & $\begin{array}{l}0.0001 \mathrm{i} \\
(0.0001,0.0001)\end{array}$ & * & * & * & $*$ & \\
\hline \multicolumn{8}{|c|}{ Flight b242, 28 August 2006, dust over Atlantic Ocean north of Dakar } \\
\hline b242 R1.1 & $4 \mathrm{~km}$ & $0.0026 \mathrm{i}(0.0010,0.0044)$ & $\begin{array}{l}1.51- \\
0.0031 \mathrm{i}\end{array}$ & $\begin{array}{l}1.55- \\
0.0029 \mathrm{i}\end{array}$ & $\begin{array}{l}1.49- \\
0.0022 \mathrm{i}\end{array}$ & $\begin{array}{l}1.54- \\
0.0019 \mathrm{i}\end{array}$ & * \\
\hline b242 R5.1 & $4 \mathrm{~km}$ & $\begin{array}{l}0.0042 \mathrm{i} \\
(0.0008,0.0100)\end{array}$ & $\begin{array}{l}1.52- \\
0.0035 \mathrm{i}\end{array}$ & $\begin{array}{l}1.56- \\
0.0034 \mathrm{i}\end{array}$ & $\begin{array}{l}1.50- \\
0.0025 \mathrm{i}\end{array}$ & $\begin{array}{l}1.54- \\
0.0022 \mathrm{i}\end{array}$ & * \\
\hline
\end{tabular}

at M'Bour. This data has been selected at times when it was clear from the aircraft vertical profile at Dakar that the dust in the Dakar region had the same vertical profile as that measured during the main part of the flight, thereby increasing the chances that the dust over the AERONET station had the same characteristics as the dust intensively sampled during the flight. Profiles of carbon monoxide and ozone measured by the aircraft were also analysed to assess whether local contamination from Dakar itself could be affecting the AERONET measurements, and were not found to be a factor. Comparisons with dry season data are not used due to contamination of AERONET data by biomass burning aerosols which are present at elevated levels throughout that season (e.g. McConnell et al., 2008). Aerosol optical depths measured by AERONET at 440nm at the times used here are greater than 0.5 , therefore the uncertainties on the AERONET refractive indices are \pm 0.04 for $n_{r}$, and $30 \%$ to $50 \%$ for $n_{i}$ (Dubovik et al., 2002).
The AERONET $n_{i}$ values show relatively good agreement with the $n_{i}^{550}$ values derived from Mie code, despite firstly the AERONET data representing a column average while the aircraft measurements representing a specific dust layer, and secondly the AERONET data representing a wider size range. Additionally the AERONET retrievals are at different wavelengths to the aircraft measurements. For flight b237 there were two different layers of dust (as shown in McConnell et al., 2008, Fig. 5) with different absorption properties (see Fig. 1 for $n_{i}^{550}$ values at different altitudes). A linearly interpolated AERONET value of $n_{i}$ at $550 \mathrm{~nm}$ of $0.0024 \mathrm{i}$ is slightly larger than the Mie-derived values from the more absorbing upper layer $(0.0014 \mathrm{i}-0.002 \mathrm{i})$, but still falls within their bounds of uncertainty. For the b238 results the values of $n_{i}$ from AERONET of $0.0014 \mathrm{i}$ and $0.0008 \mathrm{i}$ at $440 \mathrm{~nm}$ and $675 \mathrm{~nm}$ respectively fall within the range of Miederived $n_{i}^{550}$ values from dust layers at different altitudes, which range from $0.0001 \mathrm{i}$ at $5 \mathrm{~km}$ to $0.0019 \mathrm{i}$ at $1 \mathrm{~km}$. The 
real part from AERONET of 1.52 falls within the range of 1.50 to 1.54 suggested by the filters results.

\subsection{Air mass origins}

Figures 2 and 3 show the origins of the air within which the dust was sampled during the dry and the wet season respectively. It is clear that the potential dust sources differed for the various dust cases, which would imply potentially different chemical composition for the different runs. For the dry season (Fig. 2), the b168 R15 and R16 cases have more southerly sources than the other runs, which may be linked to the greater absorption for these cases (as shown in Fig. 1), since Sahelian sources are expected to contain a greater content of absorbing iron oxides (e.g. Claquin et al., 1999). Note that although the dust layer found in flight b168 was below an elevated layer of biomass burning aerosol, no biomass burning particles, or evidence of mixing, was observed, based on aerosol mass spectrometer measurements and based on the techniques described here.

The wet season dust sources (Fig. 3) are much more varied than those during the dry season, which is consistent with the $n_{i}^{550}$ values being much more varied. Notably the sources for b241 R2, b242 R1.1 and b242 R5.1 are more southerly, and this can potentially be linked to $n_{i}^{550}$ being much larger for the b242 data in Fig. 1.

Dust was also found over the ocean within the marine boundary layer (below $1 \mathrm{~km}$ ) for the cases of b237 R4, b237 R5 and b241 R5. Figure 1 shows that this dust had low absorption $\left(n_{i}^{550}<0.0005 i\right)$. The NAME air mass origins demonstrate that this air originated from the northeast (Fig. 3), although since the NAME results do not include deposition, it is not clear whether this dust was transported at low levels or deposited from higher altitudes. If it is the case that this low altitude dust was transported from the northeast (in a similar manner to the dry season cases, Fig. 2), below the main elevated Saharan Air Layer, then these results imply that the sources in northwest Africa (specifically Northwest Sahara and Morocco, but not Mauritania) produce less absorbing dust than the other African sources sampled during DODO. It is also possible that if this low altitude dust was deposited from the SAL, it may have had different composition to the upper layer, if the composition varied with size, and if deposition of a particular particle size dominated. The correlations between iron oxide, soluble iron (therefore potentially bioavailable), and total iron are not entirely clear for a variety of sources. However, differences in the composition of this lower layer would be likely to influence both absorption and ocean biochemistry.

Thus there is a clear link between the different chemical composition of potential dust source regions and the Miederived values of $n_{i}^{550}$. It follows that source location also has a strong influence on the single scattering albedo, and this may explain a large part of the variability seen in the literature.

\subsection{Refractive index dependence on $\omega_{0}$ and size distribution}

The large uncertainties in the radiative effect of dust in the literature partly stem from uncertainties in the optical properties, which are inherently dependent on the refractive index and on the size distribution, as previous modeling studies have demonstrated (e.g. Tegen and Lacis, 1996; Liao and Seinfeld, 1998; Sokolik and Toon, 1999; Balkanski et al., 2007). We now use measurement-based data from DODO to constrain the influences of size distribution and refractive index on the optical properties. These relationships have been examined, firstly by comparing the relationship between $\omega_{0}^{550}$ and the size distribution, and secondly by comparing the relationship between $\omega_{0}^{550}$ and the imaginary part of the refractive index. This allows the relative influence of both $n_{i}^{550}$ and the size distribution on $\omega_{0}^{550}$ to be examined.

In order to represent the size distribution using a single measurement, the effective radius (for the accumulation mode only), $\left(r_{\text {eff }}\right)$, has been calculated, (e.g. as in Pierangelo et al., 2005 and Petzold et al., 2009). Figure 4 shows the relationship between $r_{\text {eff }}$ and $\omega_{0}^{550}$ for the accumulation mode. There appears to be no relationship between the two parameters, suggesting that the variation in size distribution plays little role in determining $\omega_{0}^{550}$ for the accumulation mode, which ranges from 0.93 to 0.999 . Alternatively it is possible that the size distribution needs to be defined more subtly than by $r_{\text {eff }}$ for a relationship to emerge.

Figure 5 shows the relationship between $n_{i}^{550}$ and $\omega_{0}^{550}$. In contrast to Fig. $4, n_{i}^{550}$ derived from Mie code (solid circles) and $\omega_{0}^{550}$ show a strong linear relationship with a linear Pearsons correlation coefficient of -0.987 . This suggests that for the accumulation mode particles measured during DODO, $\omega_{0}^{550}$ was almost entirely determined by the refractive index (the chemical composition). The small amount of scatter in Fig. 5 can be interpreted as the variation in $\omega_{0}^{550}$ due to changes in the size distribution.

Figure 5 also shows the $n_{i}^{550}$ values as derived from the filter samples, for the different mineral combinations tested. On first inspection, the filters results do not conform to the linear relationship as well as the Mie-derived results. However, for the b242 results ( $\omega_{0}^{550}$ values of 0.957 and 0.946), the general linear trend of lower $n_{i}^{550}$ and higher $\omega_{0}^{550}$ is followed by the filters results. For the b238 results $\left(\omega_{0}^{550}\right.$ values of $0.980,0.974$ and 0.984 ), the linear trend is not followed by the filters results. However, this can possibly be explained by the large amount of coarse mode present during flight b238, which could have different composition to the accumulation mode. The coarse mode for flight b238 was measured during a large dust storm over Mauritania and was substantial, whereas it was much smaller for flight b242, where elevated dust was sampled over the ocean.

These results therefore suggest that the variations within the accumulation mode size distributions observed during 

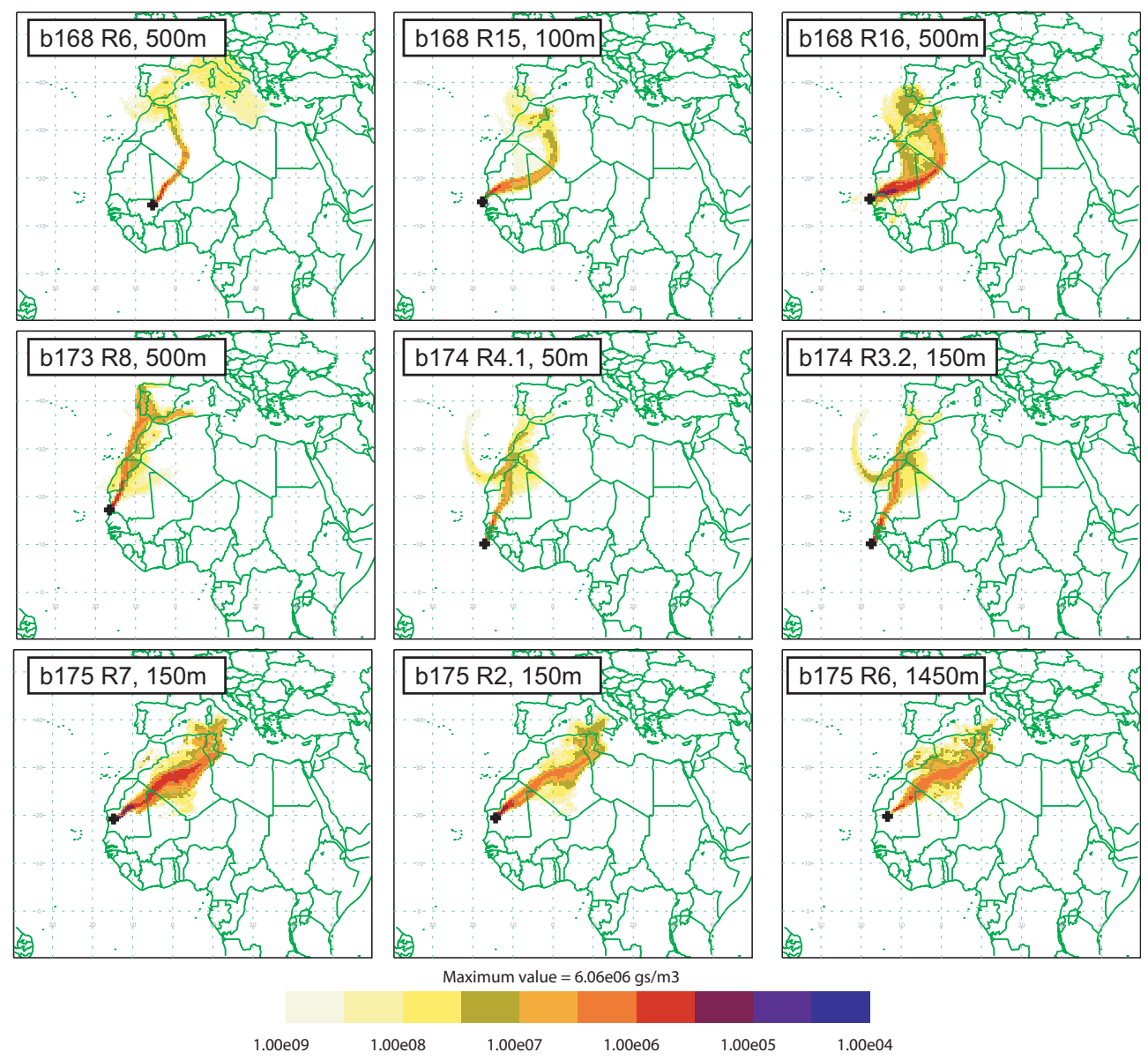

Fig. 2. Air mass origins from NAME for dust measured during the dry season (DODO1). Plus sign shows the location of the aircraft where the dust for each run was measured, which is also where NAME was initiated.

DODO had little effect on $\omega_{0}^{550}$, which was more influenced by changes in refractive index, which are likely to be caused by differing sources. Despite the size distributions being more varied during the wet season (as shown in McConnell et al., 2008) this had little effect on $\omega_{0}^{550}$. However, this does not exclude the possibility that greater fluctuations in the size distribution than were observed during DODO might have an effect on $\omega_{0}^{550}$ in other dust events. Additionally the measurements presented here for the Mie-derived $n_{i}^{550}$ values, $r_{\text {eff }}$, and $\omega_{0}^{550}$ cover the accumulation mode only and it is to be expected that the coarse mode size distribution will have a large effect on $\omega_{0}^{550}$ (e.g. McConnell et al., 2008; Otto et al., 2007).

\section{Radiative validation of refractive index for flight b238}

In order to test the different refractive indices shown in Sect. 3 further, and also to test the differences between the internal and external mixing assumptions, the refractive indices from flight b238 (under heavy dust conditions over Maurita- nia) are used in ES96 to compute irradiances which can be compared to irradiances measured on the aircraft at a range of altitudes.

\subsection{Spectral refractive indices}

ES96 requires optical properties to be specified over the spectral range used $(0.2$ to $10 \mu \mathrm{m})$, and therefore the refractive index must also be specified over this spectral range. The refractive indices from Sect. 3 from the filter samples using internal mixing are available over these wavelengths. The filters data used are from b238 R4.1, and their spectral values for each case tested (HI_int, HK_int, GI_int and GK_int) are shown in Fig. 6. However, the Mie-derived refractive indices are available only at $0.55 \mu \mathrm{m}$ and therefore require extending spectrally.

For the Mie-derived $n_{r}$ values, the WMO (1986) values shown in Fig. 6a have been used directly. For the Miederived $n_{i}$ values, the $n_{i}^{550}$ values shown in Fig. 1 for each run in flight b238 have been averaged, resulting in a b238 flight average $n_{i}^{550}$ value of $0.0012 \mathrm{i}$. The spectral variability 

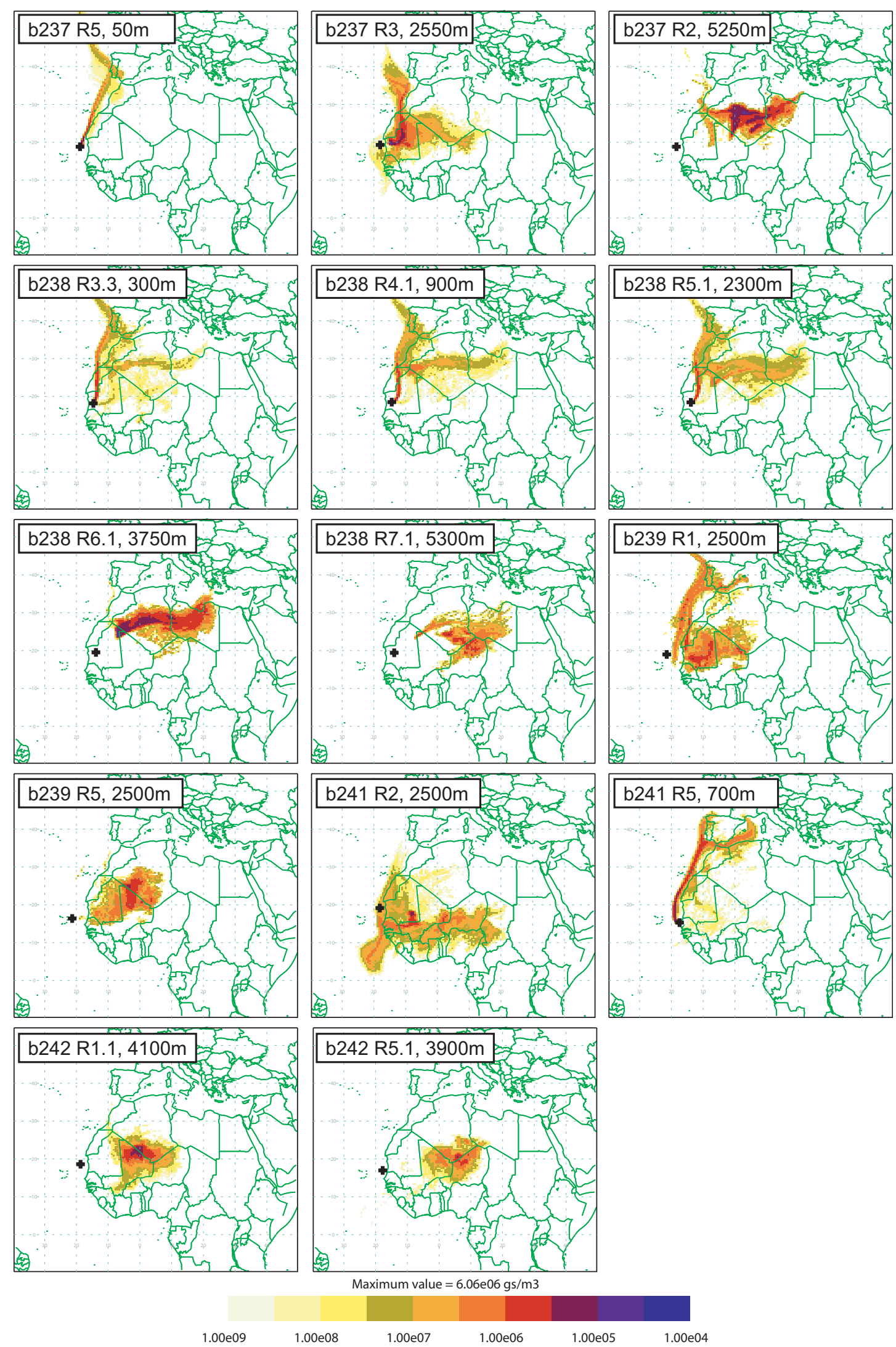

Fig. 3. Air mass origins from NAME for dust measured during the wet season (DODO2). Plus sign shows the location of the aircraft where the dust for each run was measured, which is also where NAME was initiated. 


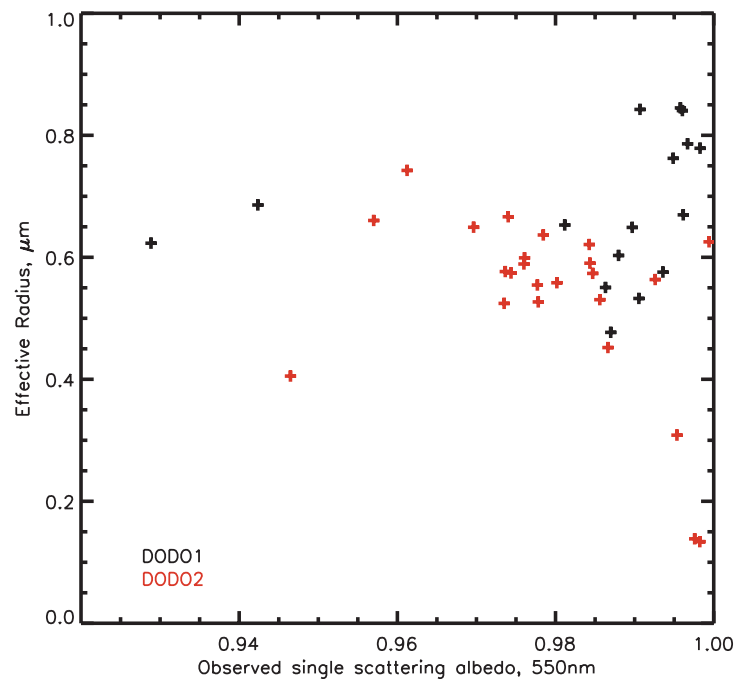

Fig. 4. Measured $\omega_{0}^{550}$ for the accumulation mode and accumulation mode effective radius.

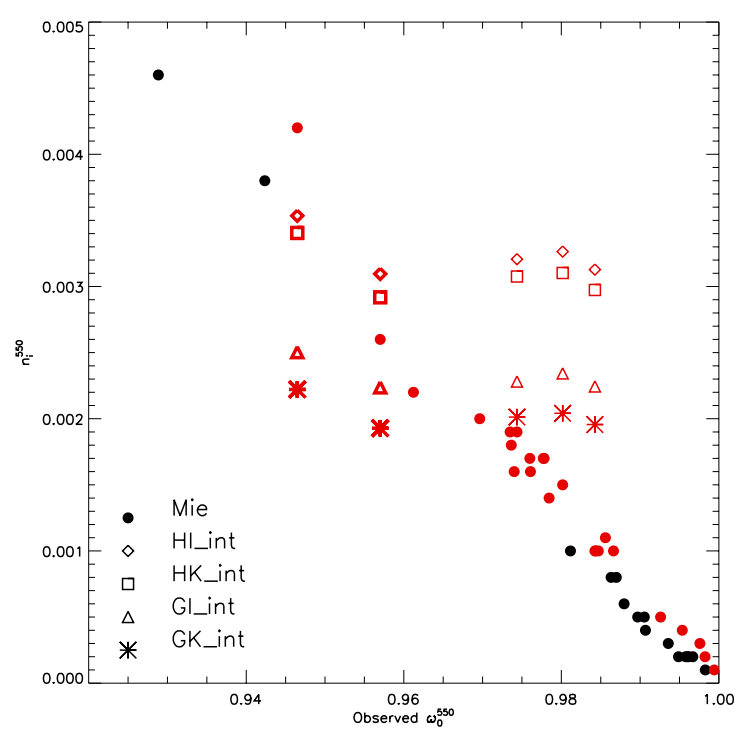

Fig. 5. Relationship between $n_{i}^{550}$ and $\omega_{0}^{550}$ for the accumulation mode. Black indicates dry season dust, red indicates wet season dust. Solid circles indicate Mie-derived $n_{i}^{550}$ values, other symbols indicate $n_{i}^{550}$ from filter sample measurements assuming internal mixing, with mineral combinations assumed as indicated in the figure. Values calculated from filter samples for flight b242 are shown in bold and filter sample values from flight b238 are shown as outlines.

has then been introduced by scaling the WMO 1986 series to the average flight value at $550 \mathrm{~nm}$ whilst retaining the same spectral variation (see the dotted line in Fig. 6a). Note that this results in significantly less absorbing dust than suggested by the WMO 1986 and Otto et al. (2007) data (which is a moving average of spectral refractive indices from Patterson et al., 1977; Carlson and Benjamin 1980; Sokolik et
Table 4. Lognormal mode parameters used to represent the size distribution for dust from flight b238.

\begin{tabular}{llll}
\hline Mode & $r_{p g} / \mu \mathrm{m}$ & $\sigma_{g}$ & $w$ \\
\hline 1 & 0.061 & 1.47 & 0.628 \\
2 & 0.154 & 1.23 & 0.224 \\
3 & 0.235 & 1.51 & 0.134 \\
4 & 0.980 & 1.32 & 0.011 \\
5 & 1.900 & 1.70 & 0.003 \\
\hline
\end{tabular}

al., 1993; Sokolik et al., 1998). We note that the scaling of the WMO $n_{i}$ series may not be physically realistic at wavelengths away from $550 \mathrm{~nm}$, where the Mie $n_{i}$ values are derived, but this spectral extrapolation is necessary input for the radiative transfer modeling, so we use this method for lack of further information, and also point out that the $n_{i}$ values around $550 \mathrm{~nm}$, where solar radiation intensity is highest, are most important.

\subsection{Spectral optical properties}

We now compare the spectral optical properties of the five cases shown in Fig. 6 (Mie-derived, HI_int, HK_int, GI_int and GK_int) and also the optical properties of the cases assuming external mixing (HI_ext, HK_ext, GI_ext and GK_ext). For the Mie and internal mixing cases, the optical properties are generated with a Mie scattering code, using the refractive indices shown in Fig. 6. For the external mixing cases, the optical proprties for quartz, calcite and iron oxide clay aggregates are calculated individually, and then weighted and summed using the values for b238 R4.1 shown in Table 2 (as described in Sect. 2.3) to generate spectral optical properties representative of the full external mixture.

The size distribution used for all cases is the same, and covers both the accumulation mode and the coarse mode (diameters of $0.01-60 \mu \mathrm{m})$. The measurements are averaged over horizontal runs at various altitudes ranging from $300 \mathrm{~m}$ to $5000 \mathrm{~m}$ and are obtained from a PCASP and a Cloud Droplet Probe (as described in McConnell et al., 2008). The size distribution has also been fitted with 5 lognormal modes, which are described in Table 4. Note that since the Mie-derived refractive indices provide information on the accumulation mode (diameter $<3 \mu \mathrm{m}$ ) only, and therefore the use of the full size distribution with these refractive indices makes the assumption that the refractive index is constant with particle size. For comparison, optical properties using the flight average size distribution for the accumulation mode only and Mie-derived refractive indices have also been calculated. The optical properties calculated from filter sample refractive indices (HI, HK, GI and GK - both internal and external mixing) all use the full size distribution. 

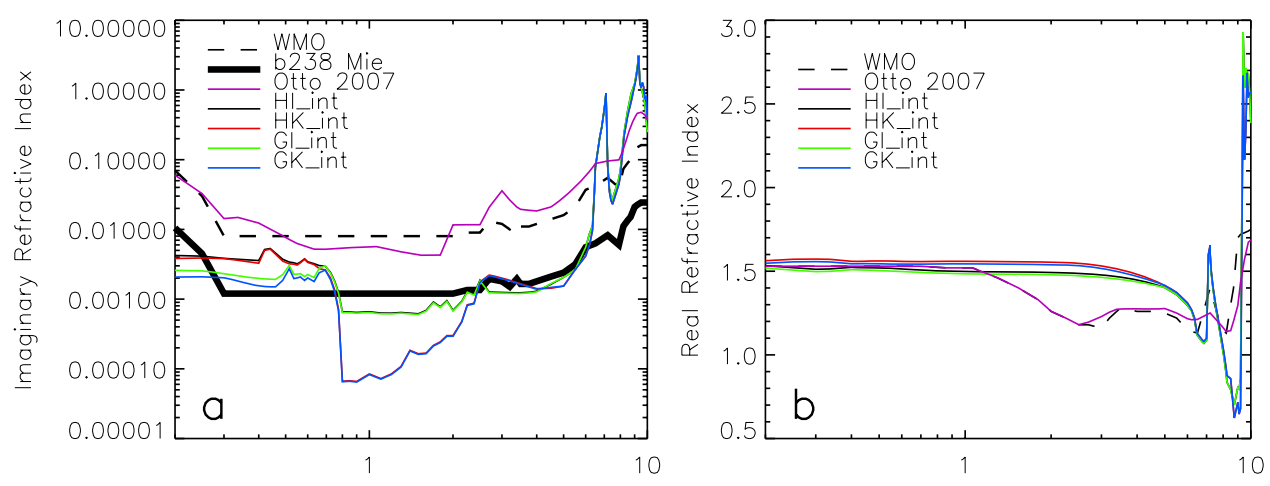

Fig. 6. Spectral Refractive indices ((a) imaginary part; (b) real part) used to generate b238 dust optical properties, for Mie-derived data, and filter sample data using different mineral combinations and assuming internal mixing. Also shown is the WMO (1986) refractive index data, and data from Otto et al. (2007), representative of various literature values.
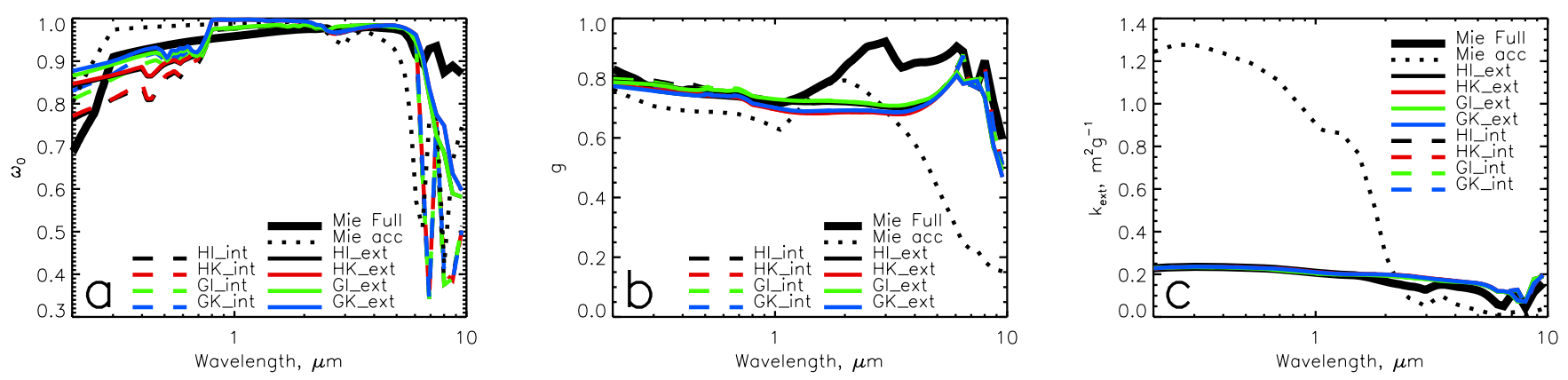

Fig. 7. Spectral optical properties for dust from flight b238. (a) Single scattering albedo, (b) asymmetry parameter, (c) mass specific extinction $\left(\mathrm{m}^{2} \mathrm{~g}^{-1}\right)$. Optical properties resulting from refractive indices from Mie-derivations and filter sample calculations are shown. Optical properties resulting from Mie-derived refractive indices are shown for a size distribution including only the accumulation mode, extending to $3 \mu \mathrm{m}$ diameter (Mie acc), and for a full size distribution extending to $60 \mu \mathrm{m}$ diameter (Mie full). For filter sample data, results from both internal mixing (int) and external mixing (ext) are shown.

The resulting spectral optical properties from each case are shown in Fig. 7, and values at 550nm are shown in Table 5. The different refractive indices result in different values of $\omega_{0}$, with the HI int case being the most absorbing $\left(\omega_{0}^{550}=0.87\right)$ and the GK_ext, GI_ext and Mie-derived with full size distribution case being the least absorbing $\left(\omega_{0}^{550}=0.92,0.92\right.$ and 0.94 respectively). This is in agreement with the HI int $n_{i}$ values shown in Fig. 6 being the largest (most absorbing), and the GK int and Mie-derived values being the smallest (least absorbing) across the wavelengths of peak solar radiation. Additionally the spectral shape of the refractive indices for the different minerals is evident in the spectral $\omega_{0}$ values, with high values at wavelengths between $1-2 \mu \mathrm{m}$, particularly for the kaolinite cases, where the $n_{i}$ values are very low. Less spectral variation is seen for the Mie cases, where the refractive index is spectrally constant between $0.3-2 \mu \mathrm{m}$. Differences in single scattering albedo between internal and external mixing assumptions are also observed. External mixtures result in higher $\omega_{0}^{550}$ values ranging from 0.01 to 0.03 compared to internal mixtures.
The addition of the coarse mode to the size distribution results in a significant decrease in $\omega_{0}$, with a change from 0.98 to 0.94 at $550 \mathrm{~nm}$ when the Mie-derived refractive indices are used. Thus the $\omega_{0}$ values shown in Fig. 7 and Table 5 are lower than those shown in Fig. 4, which represent only the accumulation mode. Very little difference is seen in the mass specific extinction, $k_{\text {ext }}$, for the different refractive indices. $k_{\text {ext }}$ is most sensitive to the size distribution used, with a large decrease when the coarse mode is present as a result of the larger particles being less efficient at extinction per unit mass. The asymmetry parameter shows some sensitivity to the refractive indices used, but the spectral variation and magnitude is more sensitive to the presence of the coarse mode.

\subsection{Vertical profile of dust}

The vertical profile of the dust mass mixing ratio is required by ES96, and is shown in Fig. 8 for flight b238. This is obtained from vertical profiles made by the aircraft where scattering at $550 \mathrm{~nm}$ from the accumulation mode was 
Table 5. Optical properties for b238 flight average dust at 550nm, for different refractive indices. All cases use the full (accumulation and coarse mode) size distribution, except where indicated. For filter sample results, both internal (int) and external (ext) mixing assumptions are shown.

\begin{tabular}{lllll}
\hline Refractive Index Approach & Size Distribution & $\omega_{0}^{550}$ & $\mathrm{~g} 550$ & $\mathrm{k}_{\text {ext }}^{550}\left(\mathrm{~m}^{2} \mathrm{~g}^{-1}\right)$ \\
\hline Mie-derived & Accumulation mode & 0.98 & 0.69 & 1.18 \\
Mie-derived & Full & 0.94 & 0.74 & 0.23 \\
HI_int, HI_ext & Full & $0.87,0.90$ & $0.77,0.76$ & $0.23,0.23$ \\
HK_int, HK_ext & Full & $0.88,0.90$ & $0.75,0.74$ & $0.23,0.23$ \\
GI_int, GI_ext & Full & $0.90,0.92$ & $0.77,0.76$ & $0.23,0.23$ \\
GK_int, GK_ext & Full & $0.91,0.92$ & $0.75,0.76$ & $0.23,0.23$ \\
\hline
\end{tabular}

Table 6. Aerosol optical depth at 550nm $\left(\tau^{550}\right)$ and diurnally averaged shortwave aerosol radiative effect (ARE) for the different refractive indices tested, at the top of atmosphere (TOA) and surface (SFC), and atmospheric heating (ATM). AREs normalized by optical depth are also shown.

\begin{tabular}{|c|c|c|c|c|c|c|c|c|c|}
\hline & HI_int & HI_ext & HK_int & HK_ext & GI_int & GI_ext & GK_int & GK_ext & Mie \\
\hline$\tau^{550} / \mathrm{Wm}^{-2}$ & 1.72 & 1.72 & 1.74 & 1.74 & 1.72 & 1.71 & 1.73 & 1.73 & 1.73 \\
\hline $\mathrm{ARE}_{\mathrm{TOA}} / \mathrm{Wm}^{-2}$ & 32 & 22 & 20 & 15 & 25 & 16 & 11 & 7 & 14 \\
\hline $\mathrm{ARE}_{\mathrm{SFC}} / \mathrm{Wm}^{-2}$ & -59 & -53 & -53 & -52 & -53 & -48 & -46 & -46 & -46 \\
\hline $\mathrm{ATM} / \mathrm{Wm}^{-2}$ & 90 & 76 & 72 & 67 & 77 & 65 & 57 & 53 & 60 \\
\hline $\mathrm{ARE}_{\mathrm{TOA}} / \tau^{550} / \mathrm{Wm}^{-2} \tau^{-1}$ & 18 & 13 & 11 & 9 & 14 & 10 & 6 & 4 & 8 \\
\hline $\mathrm{ARE}_{\mathrm{SFC}} / \tau^{550} / \mathrm{Wm}^{-2} \tau^{-1}$ & -34 & -31 & -30 & -30 & -31 & -28 & -26 & -26 & -27 \\
\hline $\mathrm{ATM} / \tau^{550} / \mathrm{Wm}^{-2} \tau^{-1}$ & 52 & 44 & 42 & 39 & 45 & 38 & 33 & 31 & 35 \\
\hline
\end{tabular}

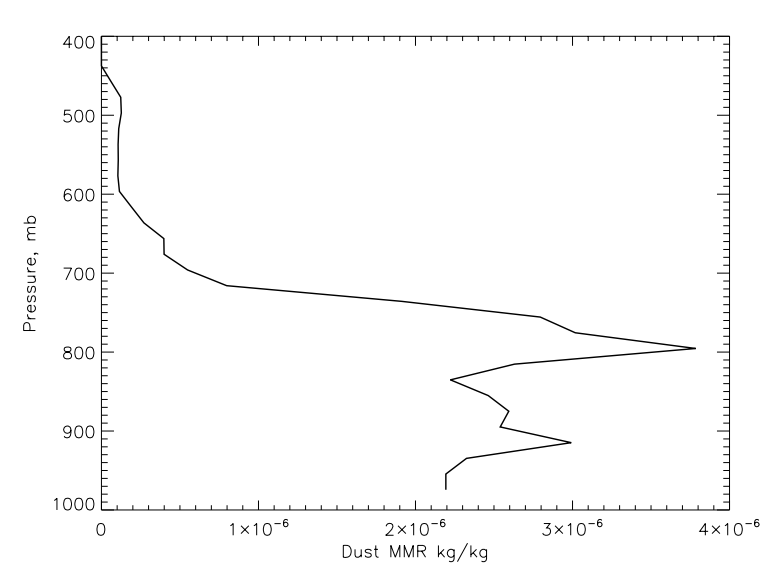

Fig. 8. Vertical profile of dust mass mixing ratio $(\mathrm{kg} / \mathrm{kg})$ as used in ES96, obtained from aircraft measurements and adjusted to include the coarse mode particles, as described in the text.

measured by a nephelometer. Using $\omega_{0}^{550}$ measurements at different altitudes, the scattering was converted to an extinction coefficient, $\sigma_{\text {ext }}\left(\mathrm{m}^{-1}\right)$ (as described in McConnell et al., 2008). The dust mass mixing ratio (MMR, in units of $\mathrm{kg} / \mathrm{kg}$ ) was then calculated using

$$
\mathrm{MMR}=\frac{\sigma_{\mathrm{ext}}^{550}}{k_{\mathrm{ext}}^{550} \rho_{\mathrm{air}}}
$$

(e.g. Greed et al., 2008), where $\rho_{\text {air }}$ is the density of air and can be calculated from standard measurements of temperature and pressure from the aircraft. In order to ensure that the dust MMR was representative of the full size distribution, rather than just the accumulation mode, the value of $k_{\mathrm{ext}}^{550}$ was calculated at specific altitudes and incorporated the full size distribution. Since the lower portion of the vertical profile contained more large particles, $k_{\mathrm{ext}}^{550}$ increased with altitude, and therefore the mass mixing ratio is much greater at lower altitudes.

\subsection{Comparison of modelled and measured irradiance}

The optical properties for the cases of HI, HK, GI, GK (both internal and external) and Mie Full shown in Sect. 4.2 have been used in ES96 to compute irradiances at various altitudes and solar zenith angles so that they are comparable to measurements from the pyranometers on the aircraft. Note that all these combinations incorporate the full (accumulation mode and coarse mode) size distributions.

Table 6 shows that the aerosol optical depths at $550 \mathrm{~nm}$ resulting from the model calculations (ranging from 1.71 to 1.74) agree well with that measured by the nephelometer 

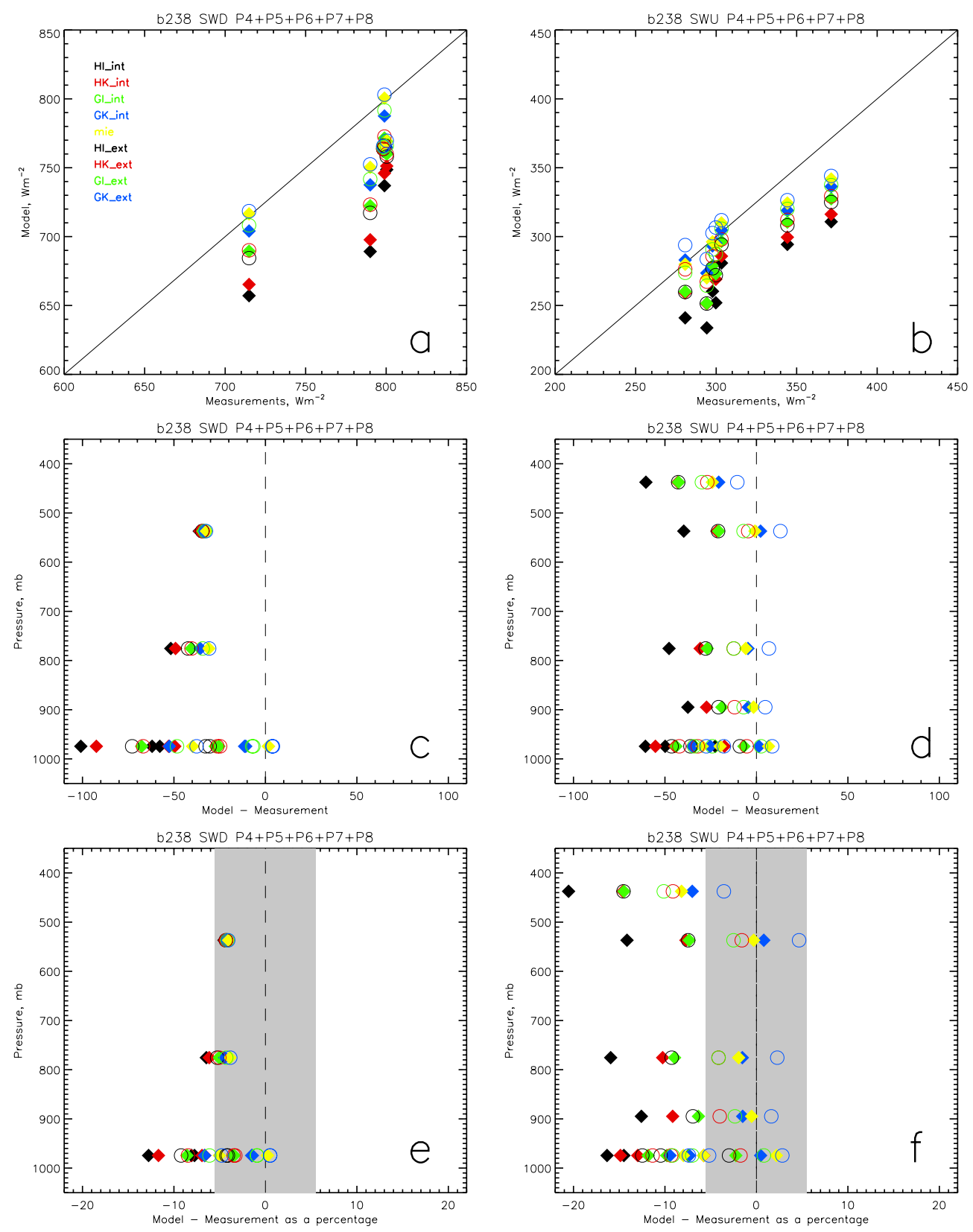

Fig. 9. Comparison of modeled and measured irradiances, for shortwave downwelling irradiance (left hand side) and shortwave upwelling irradiance (right hand side). Top row ( $\mathrm{a}$ and $\mathrm{b}$ ): scatter plots of modeled and measured irradiance; middle row (c and d): difference between modeled and measured irradiance as a function of pressure; bottom row (e and f): percentage difference between modeled and measured irradiance as a function of pressure. Grey shading indicates where agreement is within the pyranometer measurement errors (5.5\%). Different colors indicate different refractive indices used, as indicated in the figure. Solid diamonds indicate an internal mixing assumption, open circles indicate an external mixing assumption. Solid yellow diamonds indicate the results based on Mie-derived refractive indices.

(1.75 \pm 0.03$)$, suggesting that the amount of dust specified in the model is acceptable.

A comparison of the measured and modelled irradiances is shown in Fig. 9. These are shown in terms of scatter plots of model and measured irradiance (shortwave downwelling irradiance (SWD) in Fig. 9a and shortwave upwelling irradiance (SWU) in Fig. 9b), the difference between model and measured irradiance as a function of pressure (SWD in Fig. 9c and SWU in Fig. 9d), and finally the percentage difference between model and measured irradiance as a function of pressure (SWD in Fig. 9e and SWU in Fig. 9f), since the error on the measurements (grey shading) can be shown in these terms. 
It can be seen in Fig. 9e that the modelled shortwave downwelling irradiance (SWD) at $550 \mathrm{mb}$ (above most of the dust) is in agreement with the pyranometer measurements (i.e. within the grey shading), suggesting that the model representation of the atmosphere above the dust is appropriate. At lower altitudes all the refractive indices other than HI show agreement to some extent with the measurements for SWD. This is also the case for shortwave upwelling (SWU) irradiance for the lowest altitude measurements. At higher altitudes the SWU agreement between model and measurements worsens slightly, though the best agreement at all pressures is found for the Mie, GK_int and GK_ext cases. In particular, for GK_ext there is agreement within the pyranometer uncertainties at all altitudes. The HI, HK and GI cases (internal and external mixing) result in too little SWU due to their lower $\omega_{0}$ values. This suggests that the $\omega_{0}^{550}$ values of 0.91 , 0.92 and 0.94 for the GK_int, GK_ext and Mie cases respectively are most appropriate for the b238 dust, and that the refractive indices for GK_int and Mie (0.0016i and 0.0012i) are also most appropriate.

We also note that no matter which mineral combination is used, the external mixing assumptions constantly result in better agreement with the measurements and with the Mie results, supporting the evidence that the dust was externally mixed. Clearly an accurate dust mixing representation is important for the radiation balance.

Note that the surface albedo of 0.44 has been calculated from low level pyranometer measurements of up and downwelling irradiance. Calibration of the lower pyranometer was not possible during DODO, and therefore the uncertainty in these measurements is not well defined (contrary to the upwards facing pyranometer). It is therefore possible that the worse agreement between model and measurements at higher altitudes for SWU is also in part due to unquantified pyranometer uncertainty. Nevertheless, it is clear for the SWD irradiance comparisons, where the pyranometer measurements are thought to be reliable, that the Mie and GK cases show the best results.

Additionally, the uncertainty of \pm 0.1 in the broadband surface albedo should be taken into account. Sensitivity tests showed that the SWD irradiance was not very sensitive to this uncertainty (leading to changes of under 3\%), but that the SWU irradiance was much more sensitive, leading to modelled SWU uncertainties of up to $\pm 25 \%$ at the lowest three run altitudes, and $\pm 10 \%$ at the highest two run altitudes. Therefore for the lower altitude runs, the differences in irradiance due to the different chemical compositions tested are as large as the uncertainty due to surface albedo, and should not therefore be used to help achieve radiative closure. However, the high altitude runs, where uncertainty to surface albedo is lower, can still be used for this purpose, and suggest that the best agreement is found for the Mie and GK cases, as is the case for the downwelling irradiance.

An additional uncertainty arises from the use of a spectrally constant surface albedo, where in reality the sur- face albedo may change with wavelength (e.g. Bierwith et al., 2009). Sensitivity tests using four different spectrally varying surface albedos from the ASTER spectral library (Baldridge et al., 2009) were carried out, with the data scaled so that the spectrally integrated albedo was equal to 0.44 , as measured by the pyranometers. The modeled SWD irradiances are not very sensitive to these changes (showing changes of under $2 \%$ ), while the SWU irradiances are affected to a greater degree resulting in an uncertainty of around $10 \%$ at the lower altitudes, and around $5 \%$ at the higher altitudes. As with the sensitivity study for the broadband albedo value, this means that we do not use the lower altitude SWU model results to achieve radiative closure, since the spread of results due to the different refractive indices used is as great as the model uncertainty to the surface albedo. However, the high altitude SWU results, and all of the SWD results suggest that the Mie and GK composition results provide the best closure. The good agreement shown for the Mie and GK cases, both in terms of refractive indices, and modelled and measured irradiances, is somewhat surprising given that the Mie-derived refractive indices represent only the accumulation mode, and are assumed to be the same for larger particles for the modeling comparisons, whereas the filters refractive indices are derived from samples which include coarse mode particles. For example, Otto et al. (2009) observed large changes in the imaginary part of the refractive index with particle size. The radiative modeling results suggest that for the b238 dust, there was probably not a lot of variation in refractive index as a function of particle size during this particular dust event.

The results suggest that since the GK_int and GK_ext cases give the closest agreement of the mineral combinations tested in terms of radiative closure, the most likely composition of the clay in the dust was kaolinite, and that the iron oxide was goethite. Additionally, the external mixing assumption for GK results in better agreement with the measurements than GK_int (internal mixing). The combination of kaolinite and goethite minimises the absorbing properties of the dust, as suggested by the combination of the nephelometer and PSAP measurements. Interestingly, illite is always more abundant that kaolinite (Caquineau et al., 2002). Goethite is found to be ubiquitous on mineral dust samples from the dry season (Formenti et al., 2008), although additional measurements using standards of representative composition are needed to quantify this result. Additionally, taking the GK combination as the most likely for b238, the agreement between the filters cases and the Mie-derived refractive indices shown in Fig. 1 is improved over the other combinations. In Sect. 3.1 it was hypothesised that the larger differences seen for b238 compared to b242 between the filters and Mie-derived results was due to a greater presence of coarse mode during b238. The radiative closure experiments performed here actually suggest that there was little change in composition with size during b238, and rather that the GK combination is the most likely, narrowing the difference in refractive index between 
the two techniques. These findings highlight the importance of using several different measurements and techniques simultaneously to adequately determine and validate the refractive index of mineral dust.

Table 6 shows the diurnally averaged aerosol radiative effect (ARE) that would result from the different refractive indices and mixing assumptions tested. For comparison purposes, ARE values are also given in relation to the aerosol optical depths - though comparisons with other studies are not always straightforward since the results presented here are for a single diurnally averaged case study, whereas other modeling studies often provide ARE values over longer time periods (e.g. Balkanski et al., 2007), and for case studies over different surface types, such as over ocean, which result in a very different radiative effect (e.g. Haywood et al., 2003). Note that the positive forcing at the TOA shown in Table 6 can be up to almost a factor of three greater if HI_int refractive indices are assumed $\left(\mathrm{ARE}_{\mathrm{TOA}}=+32 \mathrm{Wm}^{-2}\right)$ in comparison to GK_int refractive indices $\left(\mathrm{ARE}_{\mathrm{TOA}}=+11 \mathrm{Wm}^{-2}\right)$. This spread widens when the external mixing results are also taken into account. Additionally, the atmospheric heating increases by $58 \%$ from GK int $\left(+57 \mathrm{Wm}^{-2}\right)$ to HI_int $\left(+90 \mathrm{Wm}^{-2}\right)$, and the negative surface ARE decreases by $28 \%$ from GK_int $\left(-46 \mathrm{Wm}^{-2}\right)$ to HI_int $\left(-59 \mathrm{Wm}^{-2}\right)$. The differences between external and internal mixing are also marked - for example a decrease of $31 \%$ from HI_int $\left(+32 \mathrm{Wm}^{-2}\right)$ to HI_ext $\left(+22 \mathrm{Wm}^{-2}\right)$ in $\mathrm{ARE}_{T O A}$, and a similar decrease of $36 \%$ from internal to external mixing for the most likely mineral combination, GK. These are significant changes, and could have important effects on atmospheric circulation. This highlights the importance of using an appropriate refractive index and optical properties, and the errors that can occur, for example, if models do not take account of potentially different refractive indices of dust from different geographical sources.

\section{Conclusions}

Imaginary refractive indices for dust by $0.001 \mathrm{i}$ to $0.0046 \mathrm{i}$ for the accumulation mode have been presented. They have been derived from DODO aircraft measurements of scattering, absorption and size distribution using Mie code simulations, assuming spherical particles. These measurements agree well (within the bounds of error) with refractive indices calculated from filter samples collected during DODO, covering the accumulation mode and coarse mode, based on the methodology of Lafon et al. (2006) and assuming internal mixing, depending on the mineral combination assumed. For flight b238 radiative closure experiments suggested that the GK mineral combination was the most likely, thus narrowing the difference in $n_{i}^{550}$ between the Mie-derived refractive indices and the internally mixed filter sample refractive indices. The refractive indices also compare well to those retrieved by the Dakar AERONET station, despite the AERONET mea- surements representing a column, whereas the aircraft measures properties of dust at a specific altitude, and despite the AERONET measurements covering a slightly different size range.

The amount of agreement in the imaginary part of the refractive index calculated using the filter sample data based on internal mixing and the Mie calculations is perhaps surprising, considering the potential differences in refractive index that might occur due to size-varying composition, as found in Otto et al. (2009), for example, where large changes in the imaginary part of the refractive index were observed with particle size. The results from b238 and b242 seem to indicate that refractive index does not always change substantially with particle size. This issue will be addressed in future research.

The variations in $n_{i}^{550}$ have been shown to be linked to variations in likely dust source location. Although it was not possible to pinpoint specific sources for each case, as we have used air origins as a proxy for dust source, dust originating from different parts of Northern Africa clearly had differing amounts of absorption. This was found to be strongly related to the single scattering albedo of the accumulation mode dust, and correspondingly the different size distributions for the accumulation mode were not found to be related to the different measurements of single scattering albedo. We note however, that this conclusion does not apply to the single scattering albedo of the coarse mode size distribution, which is likely to be highly sensitive to variations in size distribution.

The measured size distributions and refractive indices selected to represent flight b238 over the Mauritanian desert have been used successfully in a radiative transfer model, generating irradiances at pressures between $975 \mathrm{mbar}$ and $440 \mathrm{mbar}$ (around $300 \mathrm{~m}$ to $6750 \mathrm{~m}$ ). These have been compared to irradiances measured at a range of altitudes by pyranometers on the aircraft, and have been found to agree (within the uncertainties of the pyranometer measurements) for the refractive indices derived from optical measurements using Mie theory, and from refractive indices measured from filter samples based on the GK mineral combination. Uncertainties in surface albedo were significant for the lower altitude shortwave upwelling irradiance, and these model results were not included when assessing the agreement between the model and measured results. Despite this, by using the SWU data at high altitudes, and SWD at all altitudes, it is has been possible to achieve "radiative closure" for dust by using refractive indices and optical properties derived from both chemical composition measurements and optical measurements, combined with radiative transfer modeling and radiometric measurements from a range of altitudes within the dust.

The aerosol radiative effect differed significantly for the different mineral combinations and mixing assumptions (internal and external) tested, for the top of atmosphere, surface, and atmospheric heating. Most notably the top of atmosphere 
radiative effect increased by a factor of three for a change of refractive index from GK_int to HI_int, and the atmospheric heating increased by $58 \%$. For the dust event examined, the GK_ext case gave the best agreement with measurements, and externally mixed cases consistently gave better agreement than internally mixed cases. Considering these large changes, and the link between refractive index and dust source location, it is therefore of crucial importance to determine how the amount of absorption differs for different geographical source locations if the radiative effect of dust is to be accurately modelled in numerical weather forecasting and climate models.

Acknowledgements. DODO is funded by the SOLAS directed program (NE/C517276/1). The authors thank Didier Tanré for his effort in establishing and maintaining the Dakar AERONET site. We acknowledge the efforts of FAAM, Directflight and Avalon Engineering during the DODO aircraft campaigns, and Phil Rosenberg (FAAM) for assistance in pyranometer data quality control. FAAM is jointly funded by the Natural Environment Research Council and the Met Office. S. Chevaillier, S. Lafon (LISA) and S. Caquineau (IRD, Bondy) are thanked for assisting with filter sample analysis. H. Brindley is thanked for discussions regarding radiative transfer modeling.

Edited by: F. Dentener

\section{References}

Baldridge, A. M., Hook, S. J., Grove, C. I., and Rivera, G.: The ASTER Spectral Library Version 2.0., Remote Sens. Environ., 113, 4, 711-715, 2009.

Balkanski, Y., Schulz, M., Claquin, T., and Guibert, S.: Reevaluation of mineral aerosol radiative forcings suggests a better agreement with satellite and AERONET data, Atmos. Chem. Phys., 7(1), 81-95, 2007.

Bédidi, A. and Cervelle, B.: Mesures spectroscopiques de laboratoire (spectroscopie optique), edited by: Ed Eska, Paris, France, 9-25, 1996.

Bierwith, E., Wendisch, M., Ehrlich, A., Heese, B., Tesche, M., Althausen, D., Schladitz, A., Muller, D., Otto, S., Trautmann, T., Dinter, T., von Hoyningen-Heune, W., and Kahn, R.: Spectral surface albedo over Morocco and its impact on radiative forcing of Saharan dust, Tellus B, 61, 252-269, 2009.

Bohren, C. F. and Huffman, D. R.: Absorption and scattering of light by small particles, Wiley Interscience, New York, USA, 311, 1983.

Caquineau, S., Gaudichet, A., Gomes, L., Magonthier, M. C., and Chatenet, B.: Saharan dust: Clay ratio as a relevant tracer to assess the origin of soil-derived aerosols, Geophys. Res. Lett., 25, 7, 983-986, 1998.

Caquineau, S., Gaudichet, A., Gomes, L., and Legrand, M.: Mineralogy of Saharan dust transported over northwestern tropical Atlantic Ocean in relation to source regions , J. Geophys. Res., 107(D15), 4251, doi:10.1029/2000JD000247, 2002.

Carlson, T. N. and Benjamin, S. G.: Radiative heating rates for Saharan dust, J. Atmos. Sci., 37, 1, 193-213, 1980.
Claquin, T., Schulz, M., and Balkanski, Y.: Modeling the mineralogy of atmospheric dust sources, J. Geophys. Res., 104, 2224322256, 1999.

Chou, C., Formenti, P., Maille, M., Ausset, P., Helas, G., Harrison, M., and Osborne, S.: Size distribution, shape, and composition of mineral dust aerosols collected during the African Monsoon Multidisciplinary Analysis Special Observation Period 0: Dust and Biomass-Burning Experiment field campaign in Niger, January 2006, J. Geophys. Res., 113, D00C10, doi:10.1029/2008JD009897, 2008.

Cullen, M. J. P.: The unified forecast/climate model, Meteorol. Mag., 122, 81-93, 1993.

Dubovik, O., Holben, B., Eck, T., Smirnov, A., Kaufman, Y., King, M., Tanré, D., and Slutsker, I.: Variability of absorption and optical properties of key aerosol types observed in world-wide locations, J. Atmos. Sci., 59, 590-608, 2002.

Edwards, J. M. and Slingo, A.: Studies with a flexible new radiation code. I: Choosing a configuration for a large-scale model, Q. J. Roy. Meteor. Soc., 122(531), 689-719, 1996.

Formenti, P., Rajot, J. L., Desboeufs, K., Caquineau, S., Chevaillier, S., Nava, S., Gaudichet, A., Journet, E., Triqute, S., Alfaro, S., Chiari, M., Haywood, J., Coe, H., and Highwood, E.: Regional variability of the composition of mineral dust from western Africa: Results from the AMMA SOP0/DABEX and DODO field campaigns, J. Geophys. Res., 113, D00C13, doi:10.1029/2008JD009903, 2008.

Forster, P., Ramaswamy, V., Artaxo, P., Berntsen, T., Betts, R., Fahey, D. W., Haywood, J., Lean, J., Lowe, D. C., Myhre, G., Nganga, J., Prinn, R., Raga, G., Schulz, M., and Van Dorland, R.: Changes in Atmospheric Constituents and in Radiative Forcing, in: Climate Change 2007: The Physical Science Basis. Contribution of Working Group I to the Fourth Assessment Report of the Intergovernmental Panel on Climate Change, edited by: Solomon, S., Qin, D., Manning, M., Chen, Z., Marquis, M., Averyt, K. B., Tignor, M., and Miller, H. L., Cambridge University Press, Cambridge, UK and New York, NY, USA, 2007.

Greed, G., Haywood, J. M., Milton, S., Keil, A., Christopher, S., Gupta, P., and Highwood, E. J.: Aerosol optical depths over North Africa: 2. Modeling and model validation, J. Geophys. Res., 113, D00C05, doi:10.1029/2007JD009457, 2008.

Haywood, J., Francis, P., Osborne, S., Glew, M., Loeb, N., Highwood, E., Tanré, D., Myhre, G., Formenti, P., and Hirst, E.: Radiative properties and direct radiative effect of Saharan dust measured by the C-130 aircraft during Saharan Dust Experiment (SHADE). 1: Solar spectrum, J. Geophys. Res., 108(D18), 8577, doi:10.1029/2002JD002687, 2003.

Highwood, E. J., Haywood, J. M., Silverstone, M. D., Newman, S. M., and Taylor, J. P.: Radiative properties and direct effect of Saharan dust measured by the C-130 aircraft during Saharan Dust Experiment (SHADE): 2. Terrestrial spectrum, J. Geophys. Res., 108(D18), 8578, doi:10.1029/2002JD002552, 2003.

Kandler, K., Benker, N., Bundke, U., Cuevas, E., Ebert, M., Knippertz, P., Rodríguez, S., Schütz, L., and Weinbruch, S.: Chemical composition and complex refractive index of Saharan Mineral Dust at Izaña, Tenerife (Spain) derived by electron microscopy, Atmos. Environ., 41, 8058-8074, 2007.

Kosmas, C. S., Curi, N., Bryant, R. B., and Franzmeier, D. P.: Characterisation of iron oxide minerals by second-derivative visible spectroscopy, Division S-9-soil mineralogy, 401-405, 1984. 
Lafon, S., Sokolik, I. N., Rajot, J. L., Caquineau, S., and Gaudichet, A.: Characterization of iron oxides in mineral dust aerosols: Implications for light absorption, J. Geophys. Res., 111, D21207, doi:10.1029/2005JD007016, 2006.

Lafon, S., Sokolik, I. N., Rajot, J. L., Caquineau, S., and Gaudichet A.: Characterization of iron oxides in mineral dust aerosols: implications for light absorption, J. Geophys. Res., 111, D21207, doi:10.1029/2005JD007016, 2006.

Liao, H. and Seinfeld, J. H.: Radiative forcing by mineral dust aerosols: sensitivity to key variables, J. Geophys. Res., 103(D24), 31637-31645, 1998.

McClatchey, R. A., Fenn, R. W., Selby, J. E. A., Volz, F. E., and Garing, J. S.: Optical properties of the atmosphere, ARCRL71-0279, Air Force Geophysics Lab, Bedford, MA, USA, p. 24, 1971.

McConnell, C. L., Highwood, E. J., Coe, H., Formenti, P., Anderson, B., Osborne, S., Nava, S., Desboeufs, K., Chen, G., and Harrison, M. A. J.: Seasonal variations of the physical and optical characteristics of Saharan dust: Results from the Dust Outflow and Deposition to the Ocean (DODO) experiment, J. Geophys. Res., 113, D14S05, doi:10.1029/2007JD009606, 2008.

McConnell, C. L.: Aircraft measurements of Saharan Dust, Ph.D. thesis, University of Reading, UK, 140-173, 2008.

Mishchenko, M.: Light-scattering by size shape distributions of randomly oriented axially-symmetrical particles of a size comparable to a wavelength, Appl. Opt., 32(24), 4652-4666, 1993.

Mishchenko, M. I., Lacis, A. A., Carlson, B. E., and Travis, L. D.: Non-sphericity of dust-like tropospheric aerosols: implications for aerosol remote sensing and climate modeling, Geophys. Res. Lett., 22, 1077-1080, 1995.

Mishchenko, M. I., Travis, L. D., Kahn, R. A., and West, R. A.: Modeling phase functions for dustlike tropospheric aerosols using a shape mixture of randomly oriented polydisperse spheroids, J. Geophys. Res., 102(D14), 16381-16847, 1997.

Osborne, S. R., Johnson, B. T., Haywood, J. M., Baran, A. J., Harrison, M. A. J., and McConnell, C. L.: Physical and optical properties of mineral dust aerosol during the Dust and Biomass-burning Experiment, J. Geophys. Res., 113, D00C03, doi:10.1029/2007JD009551, 2008.

Otto, S., De Reus, M., Trautmann, T., Thomas, A., Wendisch, M., and Borrmann, S.: Atmospheric radiative effects of an in-situ measured Saharan dust plume and the role of large particles, Atmos. Chem. Phys., 7(3), 7767-7817, 2007.

Otto, S., Bierwith, E., Weinzierl, B., Kandler, K., Esselborn, M., Tesche, M., Schladitz, A., Wendisch, M., and Trautmann, T.: Solar radiative effects of a Saharan dust plume observed during SAMUM assuming spheroidal model particles, Tellus B, 61(1), 270-296, 2009.

Patterson, E. M., Filette, D. A., and Stockton, B. H.: Complex index of refraction between 300 and $700 \mathrm{~nm}$ for Saharan aerosols, J. Geophys. Res., 82, 3153-3160, 1977.
Penner, J. E., Andreae, M., Annegarn, H., Barrie, L., Feichter, J., Hegg, D., Jayaraman, A., Leaitch, R., Murphy, D., Nganga, J., and Pitari, G.: Aerosols, their Direct and Indirect Effects. In: Climate Change 2001: The Scientific Basis. Contribution of Working Group I to the Third Assessment Report of the Intergovernmental Panel on Climate Change edited by: Houghton, J. T., Ding, Y., Griggs, D. J., Noguer, M., van der Linden, P. J., Dai, X., Maskell, K., and Johnson, C. A.: Cambridge University Press, Cambridge, UK and New York, NY, USA, 2001.

Petzold, A., Rasp, K., Weinzierl, B., Esselborn, M., Hamburger, T., Dörnbrack, Kandler, K., Schütz, L., Knippertz, P., Fiebig, M., and Virkkula, A.: Saharan dust absorption and refractive index from aircraft-based observations during SAMUM 2006, Tellus B, 61(1), 118-130, 2009.

Pierangelo, C., Mishchenko, M., Balkanski, Y., and Chédin, A.: Retrieving the effective radius of Saharan dust coarse mode from AIRS, Geophys. Res. Lett., 32, L20813, doi:10.1029/2005GL023425, 2005.

Reid, J. S., Kinney, J. E., Westphal, D. L., Holben, B. N., Ellsworth, J. W., Tsay, S., Eleuterio, D. P., Campbell, J. R., Christopher, S. A., Colarco, P. R., Jonsson, H. H., Livingston, J. M., Maring, H. B., Meier, M. L., Pilewskie, P. Prospero, J. M., Reid, E.A., Remer, L.A., Russel, P. B., Savoie, D. L., Smirnov, A., and Tanré, D.: Analysis of measurements of Saharan dust by airborne and ground-based remote sensing methods during the Puerto Rico Dust Experiment (PRIDE), J. Geophys. Res., 108(D19), 8586, doi:10.1029/2002JD002493, 2003.

Ryall, D. B. and Maryon, R. H.: Validation of the UK Met Office's NAME model against the ETEX dataset, Atmos. Environ., 32, 4265-4276, doi:10.1016/S1352-2310(98)00177-0, 1998.

Shettle, E. P. and Fenn, R. W.: Models for the aerosols of the lower atmosphere and the effects of humidity variations on their optical properties, AFCRL Tech. Rep. 79 0214, Air Force Cambridge Research Laboratory, Hanscom Air Force Base, MA, 100 pp., 1979.

Sokolik, I. N., Andronova, A., and Johnson, T. C.: Complex refractive index of atmospheric dust aerosols, Atmos. Environ., 27A, 16, 2495-2502, 1993.

Sokolik, I., Toon, O. B., and Bergstrom, R. W.: Modeling the radiative characteristics of airborne mineral aerosols at infrared wavelengths, J. Geophys. Res., 103(D8), 8813-8826, 1998.

Sokolik, I. N. and Toon, O. B.: Incorporation of mineralogical composition into models of the radiative properties of mineral aerosol from UV to IR wavelengths, J. Geophys. Res., 104(D8), 94239444, 1999.

Tegen, I. and Lacis, A. A.: Modeling of particle size distribution and its influence on the radiative properties of mineral dust aerosol, J. Geophys. Res., 101(D14), 19237-19244, 1996.

World Climate Program (WCP): A preliminary cloudless standard atmosphere for radiation computation, World Meteorological Organisation, Geneva, 1986. 